ARTICLE

\title{
Cytosolic sequestration of the vitamin $D$ receptor as a therapeutic option for vitamin D-induced hypercalcemia
}

\author{
Daniela Rovito (10 1,2,3,4, Anna Y. Belorusova (10 5, Sandra Chalhoub 1,2,3,4, Anna-Isavella Rerra1,2,3,4, \\ Elvire Guiot ${ }^{1,2,3,4}$, Arnaud Molin ${ }^{6,7}$, Agnès Linglart 7,8 , Natacha Rochel $\mathbb{B}^{1,2,3,4}$, Gilles Laverny $\mathbb{B}^{1,2,3,4 凶} \&$ \\ Daniel Metzger (1D) 1,2,3,4凶
}

The bioactive vitamin $D_{3}, 1 \alpha, 25(\mathrm{OH})_{2} D_{3}$, plays a central role in calcium homeostasis by controlling the activity of the vitamin $D$ receptor (VDR) in various tissues. Hypercalcemia secondary to high circulating levels of vitamin $D_{3}$ leads to hypercalciuria, nephrocalcinosis and renal dysfunctions. Current therapeutic strategies aim at limiting calcium intake, absorption and resorption, or $1 \alpha, 25(\mathrm{OH})_{2} \mathrm{D}_{3}$ synthesis, but are poorly efficient. In this study, we identify WBP4 as a new VDR interactant, and demonstrate that it controls VDR subcellular localization. Moreover, we show that the vitamin D analogue ZK168281 enhances the interaction between VDR and WBP4 in the cytosol, and normalizes the expression of VDR target genes and serum calcium levels in $1 \alpha, 25(\mathrm{OH})_{2} \mathrm{D}_{3}$-intoxicated mice. As ZK168281 also blunts $1 \alpha, 25(\mathrm{OH})_{2} \mathrm{D}_{3}$-induced VDR signaling in fibroblasts of a patient with impaired vitamin $D$ degradation, this VDR antagonist represents a promising therapeutic option for $1 \alpha, 25$ $(\mathrm{OH})_{2} \mathrm{D}_{3}$-induced hypercalcemia.

\footnotetext{
${ }^{1}$ Institut de Génétique et de Biologie Moléculaire et Cellulaire, IIIkirch, France. ${ }^{2}$ Centre National de la Recherche Scientifique, UMR7104 IIIkirch, France.

${ }^{3}$ Institut National de la Santé et de la Recherche Médicale (INSERM), U1258 IIlkirch, France. ${ }^{4}$ Université de Strasbourg, IIlkirch, France. ${ }^{5}$ Medicinal Chemistry, Respiratory, Inflammation and Autoimmunity, BioPharmaceuticals R\&D, AstraZeneca, Gothenburg, Sweden. ${ }^{6}$ Université de Normandie, UNICAEN, CHU de Caen Normandie, Service de Génétique, EA 7450 BIOTARGEN Caen, France. ${ }^{7}$ Reference Center for Rare Diseases of Calcium and Phosphorus Metabolism (OSCAR), Paris, France. ${ }^{8}$ Université de Paris Saclay, AP-HP, Hôpital Bicêtre, DMU SEA, INSERM, U1185, Le Kremlin Bicêtre, France. 凶email: laverny@igbmc.fr; metzger@igbmc.fr
} 
C alcium homeostasis is controlled by a network involving the parathyroid glands (PTG), intestine, kidney, and bones. At low serum calcium levels, the PTG secretes the parathyroid hormone $(\mathrm{PTH})$, which enhances the hydroxylation of $25(\mathrm{OH})$ vitamin $\mathrm{D}_{3}$ by CYP27B1 into its bioactive form $1 \alpha, 25$ $(\mathrm{OH})_{2}$ vitamin $\mathrm{D}_{3}(1,25 \mathrm{D} 3)$ in the kidney. $1,25 \mathrm{D} 3$ induces the transcriptional activity of the vitamin $\mathrm{D}$ receptor (VDR, also known as NR1I1) $)^{1,2}$, and thereby increases calcium absorption in intestine, calcium reabsorption in kidney, and calcium resorption in bones ${ }^{3}$. Importantly, high 1,25D3 levels (hypervitaminosis D) lead to hypercalcemia, and shut down PTH production in the PTG via calcium-dependent but VDR-independent pathways ${ }^{4}$.

Hypervitaminosis D in patients with granulomatous diseases, lymphomas, or vitamin D 24-hydroxylase (CYP24A1) loss-offunction mutations (also known as idiopathic infantile hypercalcemia $(\mathrm{IIH})^{5}$ ) leads to hypercalciuria, nephrocalcinosis, and renal dysfunctions ${ }^{5-8}$. Hypercalcemia in such patients can be reduced by diuretics in combination with limiting calcium and vitamin $\mathrm{D}$ intake, but in severe cases, treatments based on bisphosphonates, ketoconazole (KTZ), or glucocorticoids are required to decrease bone calcium resorption and/or intestinal calcium absorption. However, these treatments do not have sustained effects, have major drawbacks, and dramatically impact the development of children and the quality of life of patients ${ }^{6}$.

More than 3000 1,25D3 analogs were synthetized by medicinal chemistry approaches to modulate VDR activities, including many agonists and few antagonists ${ }^{9}$. Among the latter, ZK168281 (ZK), a carboxylic ester analog of 1,25D3 with a rigid extended side chain and an ethyl acrylate moiety, was shown to bind to VDR with a similar affinity than $1,25 \mathrm{D} 3^{10}$, and to reduce 1,25D3-induced gene expression in human and rat cell culture systems ${ }^{11-13}$. Moreover, crystal structure and hydrogen deuterium exchange (HDX) analyses of zebrafish VDR ligand binding domain (LBD) revealed that $\mathrm{ZK}$ does not induce the active conformation of $\mathrm{VDR}^{14}$, in agreement with previous molecular dynamic studies ${ }^{15}$. However, ZK-mediated VDR antagonistic activities in vivo, and the underlying molecular mechanisms remained to be determined.

In this work we show that $\mathrm{ZK}$ is a VDR antagonist in rat intestinal cells and in human fibroblasts, whereas CYP24A1generated $\mathrm{ZK}$ derivatives have partial agonistic activities. Importantly, ZK blunts 1,25D3-induced gene expression by enhancing the interaction of VDR with WBP4 (also known as FBP21) in the cytosol, thereby impairing its nuclear translocation. Moreover, ZK normalizes serum calcium levels in 1,25D3intoxicated mice, and 1,25D3-induced VDR signaling in fibroblasts of an IIH patient. Thus, this compound represents a potent and safe vitamin D analog for the treatment of 1,25D3-induced hypercalcemia.

\section{Results}

ZK exerts VDR agonistic and antagonistic activities. To further characterize ZK activities, IEC-18 rat intestinal epithelial cells were treated for $4 \mathrm{~h}$ with vehicle, $100 \mathrm{nM} 1,25 \mathrm{D} 3,1 \mu \mathrm{M} \mathrm{ZK}$, or a combination of both ligands. The transcript levels of the VDR target gene Cyp24a1, encoding the main 1,25D3 catabolic enzyme ${ }^{16}$, as well as those involved in calcium absorption (i.e. S100g, Atp $2 b 1$ and $\operatorname{Tr} p v 6)^{2}$ were increased by at least 3 -fold by $1,25 \mathrm{D} 3$ and by $\mathrm{ZK}$. In contrast, they were not induced by a 1,25D3 and ZK co-treatment (Fig. 1a), indicating that ZK exerts VDR agonistic and antagonistic activities.

While Cyp24a1 transcript levels were induced by 3-, 9-, and 16fold after a 2, 4, and $6 \mathrm{~h} 1,25 \mathrm{D} 3$ treatment, respectively, no induction was observed after a co-treatment with $1,25 \mathrm{D} 3$ and $\mathrm{ZK}$ at any time point (Fig. 1b). VDR protein levels were increased by
1.2- to 1.7-fold after $2-6 \mathrm{~h}$ treatments of $1,25 \mathrm{D} 3$ and $\mathrm{ZK}$, alone or in combination (Fig. 1c, d), demonstrating that ZK antagonistic activities do not result from VDR degradation. Even though VDR protein levels were higher in cells treated for $2 \mathrm{~h}$ with $\mathrm{ZK}$ than with 1,25D3 (Fig. 1c, d), ZK treatments induced Cyp24a1 transcripts with a $2 \mathrm{~h}$ delay compared to $1,25 \mathrm{D} 3$ (Fig. 1b), indicating that $\mathrm{ZK}$ metabolites might exert VDR agonistic activities. As cytochrome P450 enzymes not only induce 1,25D3 catabolism, but also enhance the activity of some vitamin $\mathrm{D}$ analogs ${ }^{16}$, the effects of ZK were determined in IEC-18 cells pretreated with $\mathrm{KTZ}$, a broad-spectrum inhibitor of such enzymes ${ }^{17}$. Under these conditions, ZK-induced VDR target gene expression was abolished, while its antagonistic activities on 1,25D3-induced genes were not affected (Fig. 1a), indicating that ZK derivatives produced in cells, but not the parent compound, have VDR agonistic activities. To investigate whether $\mathrm{ZK}$ modifications are CYP24A1 dependent, ZK activities were determined in fibroblasts from an adult patient with hypercalcemia carrying CYP24A1 loss-of-function mutations ${ }^{18}$ (FB-CYP) and in the human fibroblastic cell line FB-789 ${ }^{19}$, used as control. CYP24A1 protein was detected in FB-789, but not in FB-CYP cells (Fig. 1e), demonstrating that the mutations induce protein loss. $\mathrm{ZK}$ prevented 1,25D3-induced CYP24A1 transcripts in both cell types, but induced CYP24A1 transcripts only in FB-789 cells (Fig. 1f). Thus, ZK is a potent VDR antagonist, and its CYP24A1generated metabolite(s) exert agonistic activities.

ZK impairs 1,25D3-induced VDR nuclear translocation. VDR regulates the expression of target genes as a heterodimer with retinoid $\mathrm{X}$ receptors $(\mathrm{RXRs})^{20}$, and RXR was shown to be required for ZK-induced VDR antagonism ${ }^{11}$. To characterize conformational changes of VDR/RXR heterodimers upon $\mathrm{ZK}$ binding, we performed HDX coupled with mass spectrometry (MS) analyses using full-length hVDR and N-terminal domain truncated hRXRa (hRXRa $\Delta$ NTD) [Supplementary Table 1 and Source Data]. No detectable perturbation was observed in the DNA binding domain (DBD) of hRXRa (Supplementary Fig. 1a) and of hVDR (Fig. 2a and Supplementary Fig. 1b) upon binding of either $1,25 \mathrm{D} 3$ or $\mathrm{ZK}$. Moreover, deuterium exchange rates of the dimerization interface that involves residues from helices $(\mathrm{H})$ 7, H9, and $\mathrm{H} 10$ and of the loop between $\mathrm{H} 8$ and $\mathrm{H} 9$ of both proteins ${ }^{21,22}$ were similar upon 1,25D3 and ZK binding (Fig. 2a, b and Supplementary Fig. 1a-f). In addition, surface plasmon resonance (SPR) revealed that the affinity of the LBD of hVDR (aa 118-427) for that of hRXRa (aa 223-462) increased to a similar extent upon $\mathrm{ZK}$ and 1,25D3 binding (Supplementary Fig. 1g, h). Thus, 1,25D3- and ZK-induced hVDR conformations promote $\mathrm{hVDR} / \mathrm{hRXR} \alpha \Delta \mathrm{NTD}$ heterodimer formation.

In agreement with previous results ${ }^{23}, 1,25 \mathrm{D} 3$ binding protected hVDR amino acids 224-233, 263-269, 300-307, 390-401, and 414419 located in $\mathrm{H} 3, \mathrm{H} 5, \mathrm{H} 6-\mathrm{H} 7, \mathrm{H} 10-\mathrm{H} 11$, and $\mathrm{H} 12$, respectively (Fig. 2a, c). In contrast, upon ZK binding, deuterium exchange of $\mathrm{H} 3, \mathrm{H} 5$, and $\mathrm{H} 6$ was $6-11 \%$ lower than upon 1,25D3 binding, and that of hVDR H12 was similar to that of unliganded receptor (Fig. 2a-c and Supplementary Fig. 1b). As 1,25D3-induced hVDR $\mathrm{H} 12$ folding is mandatory for VDR activity, these results show that $\mathrm{ZK}$ does not induce the hVDR active conformation, in agreement with molecular dynamic simulations ${ }^{15}$.

Importantly, the higher sequence coverage than in the previously reported HDX-MS analysis of zebrafish VDR LBD ${ }^{14}$ revealed that the binding of $1,25 \mathrm{D} 3$ protects $\mathrm{hVDR}$ residues 139 158 , encompassing a nuclear localization signal (NLS) ${ }^{24}$, from deuterium exchange (Fig. 2a, d). Deuterium exchange of the NLS was decreased by about $45 \%$ by $1,25 \mathrm{D} 3$ and by $\mathrm{ZK}$ at early time points. In contrast, after $10 \mathrm{~min}$, it was reduced only by $1,25 \mathrm{D} 3$ 

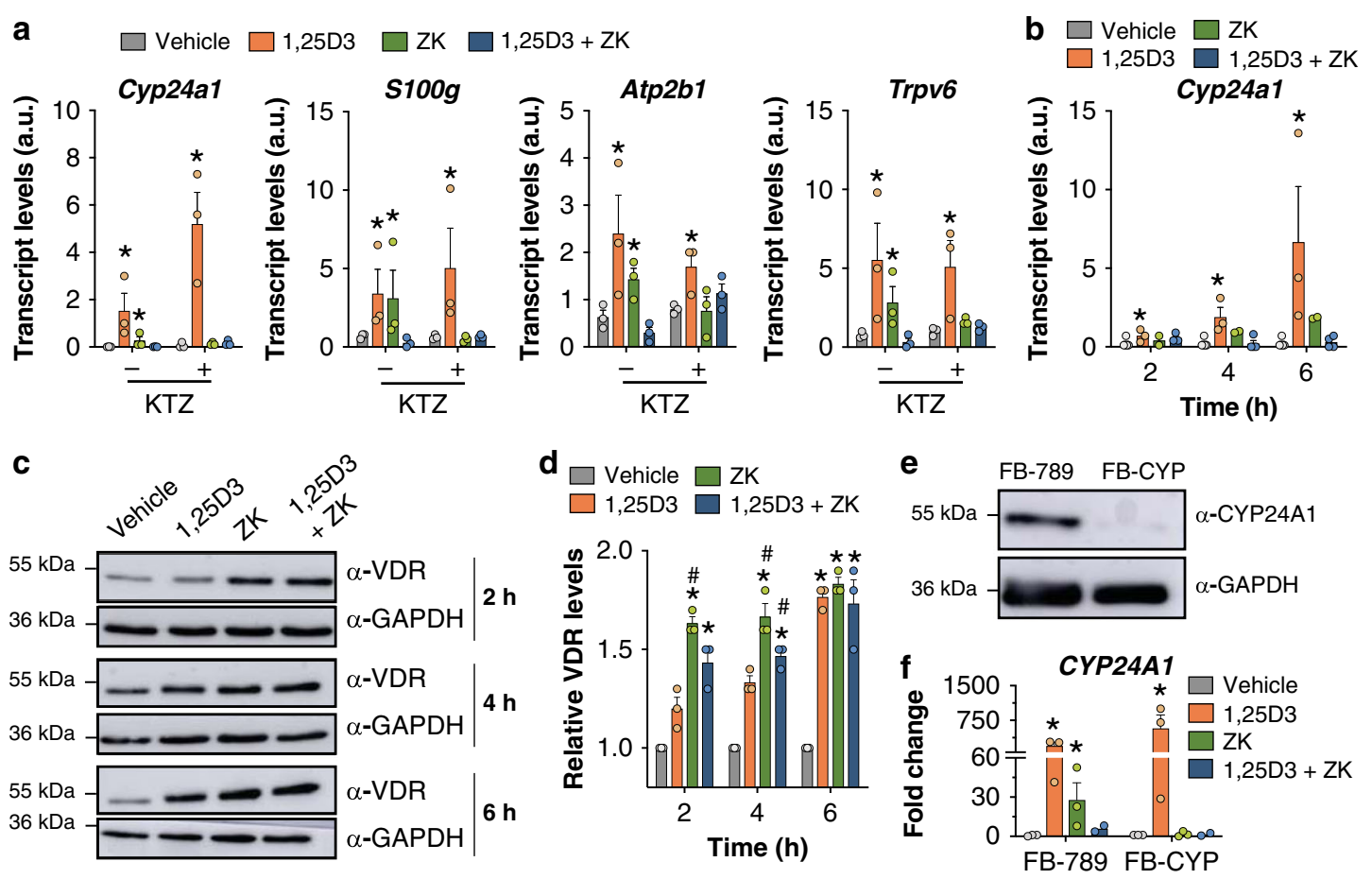

Fig. 1 ZK activities in rat intestinal epithelial cells and in human fibroblasts. a Relative transcript levels of Cyp24a1, S100g, Atp2b1, and Trpv6 after a $4 \mathrm{~h}$ treatment with vehicle, $100 \mathrm{nM}$ 1,25D3, $1 \mu \mathrm{M}$ ZK, or $100 \mathrm{nM} \mathrm{1,25D3}$ and $1 \mu \mathrm{M}$ ZK in IEC-18 cells, pre-treated (+) or not ( - ) with $5 \mu \mathrm{M}$ ketoconazole (KTZ) for $2 \mathrm{~h} . n=3$ independent biological replicates/condition. b Relative Cyp24a1 transcript levels in IEC-18 cells treated with vehicle, 100 nM 1,25D3, $1 \mu$ M ZK, or $100 \mathrm{nM} 1,25 \mathrm{D} 3$ and $1 \mu \mathrm{M}$ ZK for 2, 4, and $6 \mathrm{~h} . n=3$ independent biological replicates for vehicle, 1,25D3, and 1,25D3 and ZK. $n=2$ independent biological replicates for ZK. Representative VDR immunoblot (c) and average fold-change (d) of total extracts of IEC-18 cells treated for 2, 4, and $6 \mathrm{~h}$ with vehicle, $100 \mathrm{nM}$ 1,25D3, $1 \mu \mathrm{M}$ ZK, or $100 \mathrm{nM} \mathrm{1,25D3}$ and $1 \mu \mathrm{M} Z \mathrm{ZK} . n=3$ independent biological replicates/condition. Unprocessed blots in Source Data. e Immunoblot of CYP24A1 protein in human FB-789 and FB-CYP fibroblasts. GAPDH was used as loading control. Unprocessed blots in Source Data. f Fold change of CYP24A1 transcript levels in FB-789 and in FB-CYP fibroblasts treated for $6 \mathrm{~h}$ with vehicle, $100 \mathrm{nM} 1,25 \mathrm{D} 3,1 \mu \mathrm{M} \mathrm{ZK}$, or 100 nM 1,25D3 and $1 \mu \mathrm{M}$ ZK. The levels of vehicle-treated cells were set as reference. $n=3$ independent biological replicates/condition. Data in (a), (b), (d), and (f) are represented as mean + s.e.m. (standard error of mean). ${ }^{\star} p<0.05$ vs. vehicle, $\# p<0.05$ vs. 1,25D3; one-way ANOVA with Tukey post-hoc test. The exact significant $p$-values are provided in Supplementary Table 4.

(Fig. 2a, d, e and Supplementary Fig. 1b), indicating that ZK less efficiently stabilizes the NLS conformation.

To determine whether ZK impairs VDR intracellular trafficking, cytosolic and nuclear extracts of FB-789 cells treated for $1.5 \mathrm{~h}$ with vehicle or $10 \mathrm{nM} 1,25 \mathrm{D} 3$, or co-treated with $10 \mathrm{nM} 1,25 \mathrm{D} 3$ and $100 \mathrm{nM}$ ZK were analyzed. Cytosolic VDR levels were 2-fold lower in 1,25D3-treated than in 1,25D3 and ZK co-treated cells. In contrast, in the nuclear fraction, VDR levels were 6-fold higher in 1,25D3-treated cells than in vehicle, and a $\mathrm{ZK}$ co-treatment reduced them by 3 -fold (Fig. $3 \mathrm{a}, \mathrm{b}$ ). In agreement with these results, a ZK co-treatment reduced 1,25D3-induced VDR nuclear localization by 2 -fold in IEC- 18 cells (Fig. 3c, d). In contrast, VDR was predominantly in the nuclear fraction in the presence of $\mathrm{ZK}$ (Fig. 3c, d). Moreover, KTZ did not affect VDR localization in 1,25D3-treated, and in 1,25D3 and $\mathrm{ZK}$ co-treated cells, but impaired ZK-induced VDR nuclear localization (Fig. 3e, f), showing that ZK intracellular derivatives promote VDR nuclear translocation, and that $\mathrm{ZK}$ antagonizes 1,25D3 activities by sequestrating VDR in the cytosol.

ZK enhances the VDR/WBP4 interaction in the cytosol. To identify ZK-liganded VDR interactants that might affect VDR intracellular localization, proteins co-immunoprecipitated with cytosolic VDR from IEC-18 cells were analyzed by MS. As expected, cellular component annotations showed that most of the immunoprecipitated proteins enriched in 1,25D3, and ZK cotreated cells have a cytosolic localization (Supplementary
Table 2). Surprisingly, peptides of WBP4, a protein previously reported as a component of the spliceosome ${ }^{25,26}$, were highly enriched in $\mathrm{ZK}$ and 1,25D3 co-treated cells compared to vehicletreated cells (Fig. 4a), and were not detected in 1,25D3-treated cells (Fig. 4b). Note that none of the previously identified WBP4 nuclear partners (e.g. BRR2 and PRP8) ${ }^{27}$ were detected (full list provided as Source Data file Fig. 4a). The interaction between WBP4 and VDR was confirmed by VDR immunoblotting in WBP4-immunoprecipitated cytosolic extracts of IEC-18 and of FB-789 cells co-treated with 1,25D3 and ZK (Fig. 4c and Supplementary Fig. 2a, b). Of note, only a weak interaction between WBP4 and VDR was observed in basal conditions (Fig. 4c and Supplementary Fig. 2b).

WBP4 contains two WW domains (aa 122-196 in human) that are docking sites for proline-rich motifs ${ }^{27}$. As $\mathrm{ZK}$ destabilized VDR amino acids 152-158 encompassing a diproline motif (Fig. 2d-e), VDR might directly interact with WBP4. Native gel experiments coupled to MS analyses revealed that the WBP4 polypeptide encompassing the WW domains is bound to VDR in the presence of ZK (Supplementary Fig. 2c). Moreover, microscale thermophoresis confirmed this direct interaction, and indicated that the affinity between the two polypeptides is increased by about 2-fold in the presence of ZK (Supplementary Fig. 2d). Thus, VDR interacts with WBP4 through the two WW domains and $\mathrm{ZK}$ enhances this interaction.

Immunostaining and immunoblotting revealed that endogenous WBP4 was both nuclear and cytosolic in IEC-18 cells treated with vehicle or $1,25 \mathrm{D} 3$, and in cells co-treated with 
a

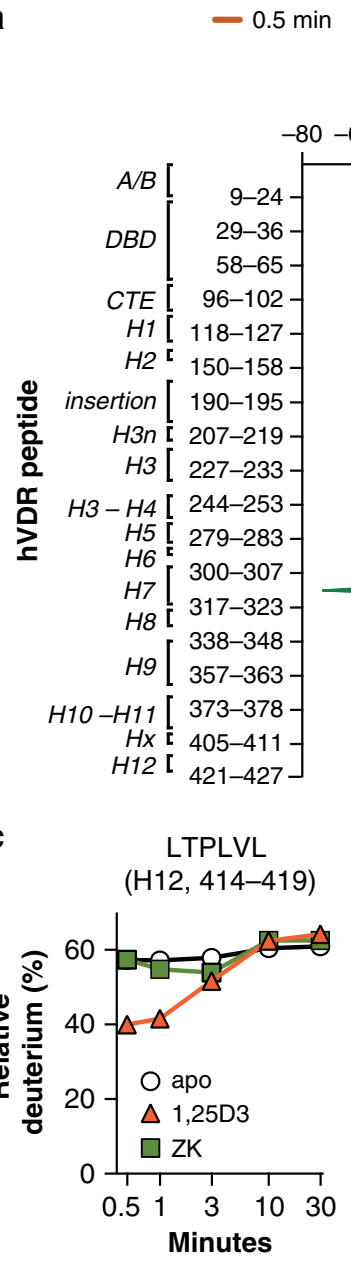

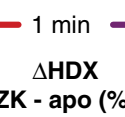

ZK - apo (\%)

$-60-40-20 \quad 0 \quad 20$

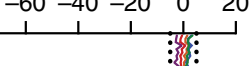

\section{1}

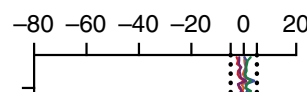

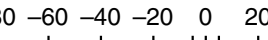

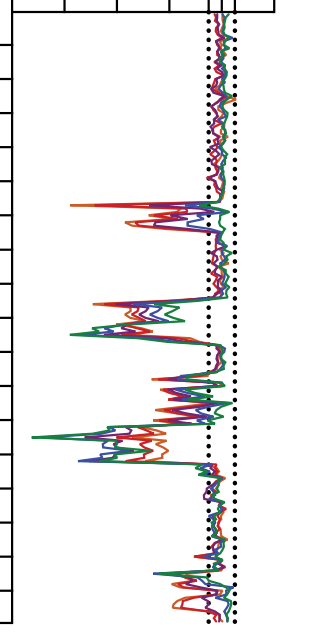

d

Q QRPPVR

(NLS, 152-158)

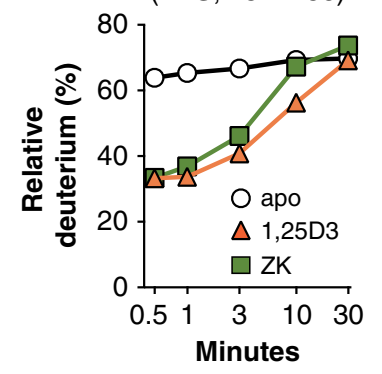

b

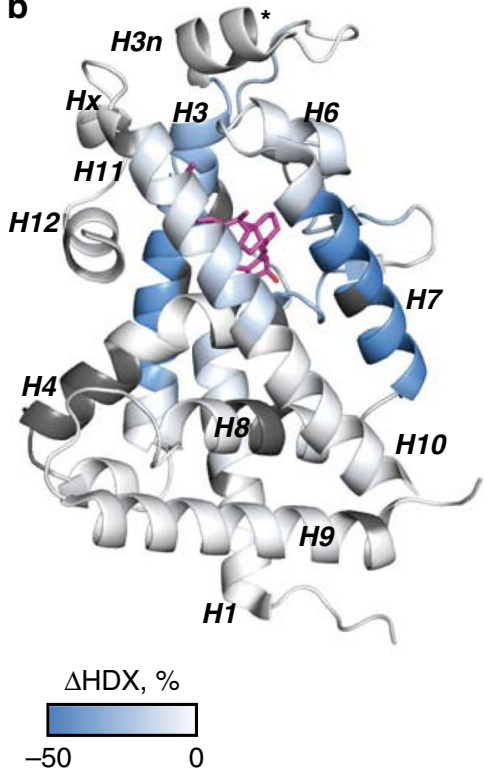

\section{e \\ 143-YDPTYSDFCQFRPPVRVNDGGGS-165}

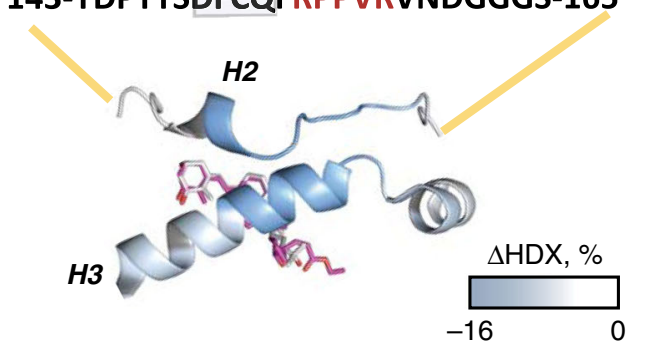

Fig. 2 Ligand-induced hVDR conformational changes. a Differential deuterium uptake ( $\triangle H D X$ ) of hVDR between apo and ZK-bound (left panel) or 1,25D3-bound (right panel) hVDR/hRXR $\Delta$ NTD heterodimers. The VDR LBD is composed of H1-H12. Negative values indicate decreased deuterium incorporation upon ligand binding. Dashed lines represent a $\Delta$ HDX of 5\%. b Average $\Delta H D X$ of hVDR between ZK-bound and apo-hVDR/hRXR $\alpha \Delta T D$ heterodimers across the various time points mapped onto hVDR LBD (PDB: 1DB1 ${ }^{44}$ ). Regions not covered by HDX-MS are shown in dark gray. Differential deuterium uptake plots of the hVDR residues 414-LTPLVL-419 located in H12 (c) and of 152-QFRPPVR-158 located in the H1-H3 loop (d) determined in ZKbound, 1,25D3-bound and apo hVDR/hRXR $\Delta$ NTD heterodimers. e Zoom of average $\Delta H D X$ across the various time points of the VDR region encompassing $\mathrm{H} 2$ and a nuclear localization signal (NLS) mapped onto the hVDR LBD (PDB: 1DB144). HDX-MS data were collected in triplicates, and deuteration data were normalized to the maximal theoretical uptake ( \pm s.e.m.).

1,25D3 and ZK (Fig. 4d and Supplementary Fig. 2e). Moreover, two molecular weight species at about $55 \mathrm{kDa}$ were detected by immunoblotting nuclear and cytosolic fractions of IEC-18, U2OS, FB-789, and HeLa cells with WBP4 antibodies (Supplementary Fig. 2e), in agreement with the manufacturer's datasheet. Note that these two protein species were differentially expressed in cytosolic and nuclear fractions. Small interfering RNA (siRNA)-mediated silencing of WBP4 in IEC-18 cells reduced its transcript and protein levels by more than $80 \%$ (Supplementary Fig. 3a, b), and markedly decreased both cytosolic and nuclear WBP4 immunostaining (Supplementary Fig. 3c, d). Importantly, VDR was mainly nuclear in WBP4-silenced cells (Fig. 4e and Supplementary Fig. 3e, f), and the transcript levels of Cyp24a1, S100g and Atp2b1 were at least 3 -fold higher than in control cells (Fig. 4f). Moreover, WBP4 silencing had almost no effect on 1,25D3-induced VDR target gene expression, but impaired ZK antagonistic activities (Fig. 4g). Thus, these results demonstrate that WBP4 modulates the distribution of VDR between the cytosol and the nucleus, and that ZK-enhanced VDR/WBP4 interaction in the cytosol underlies its VDR antagonistic activity.
ZK has a therapeutic effect for 1,25D3 intoxication. To determine the impact of $\mathrm{ZK}$ on 1,25D3-induced calcium trafficking, we analyzed the intracellular calcium flux in IEC-18 cells pre-treated

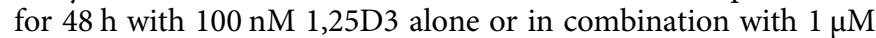
ZK. After $\mathrm{Ca}^{2+}$ addition, intracellular $\mathrm{Ca}^{2+}$ levels $\left(\left[\mathrm{Ca}^{2+}\right]_{\mathrm{i}}\right)$ were 2.5 -fold more increased in 1,25D3-treated cells than in vehicletreated cells. In contrast, $\left[\mathrm{Ca}^{2+}\right]_{\mathrm{i}}$ were similar in $1,25 \mathrm{D} 3$ and $\mathrm{ZK}$ co-treated cells, and in vehicle-treated cells (Supplementary Fig. 4), demonstrating that $\mathrm{ZK}$ hampers 1,25D3-induced calcium flux.

These results prompted us to investigate the in vivo effects of ZK. In agreement with previous results ${ }^{16}$, mice treated for 4 days with $1 \mu \mathrm{g} / \mathrm{kg} /$ day $1,25 \mathrm{D} 3$ were hypercalcemic. In contrast, serum calcium levels of mice co-treated with 1,25D3 and ZK for 4 days were similar to those of vehicle-treated mice (Fig. 5a). WBP4 was detected in cytosolic and nuclear extracts of duodenum and kidney of wild type mice (Supplementary Fig. 5a). In addition, WBP4 weakly interacted with VDR in kidney from wild-type mice (Supplementary Fig. 5b), and a 1,25D3 and ZK co-treatment enhanced this interaction (Fig. 5b). Moreover, VDR binding to vitamin $\mathrm{D}$ response elements (VDRE) located in the regulatory 
a

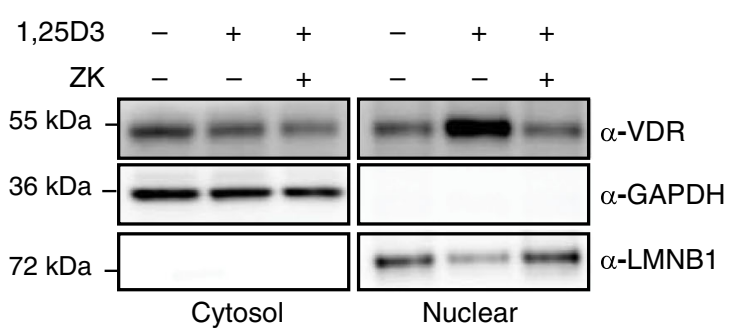

C

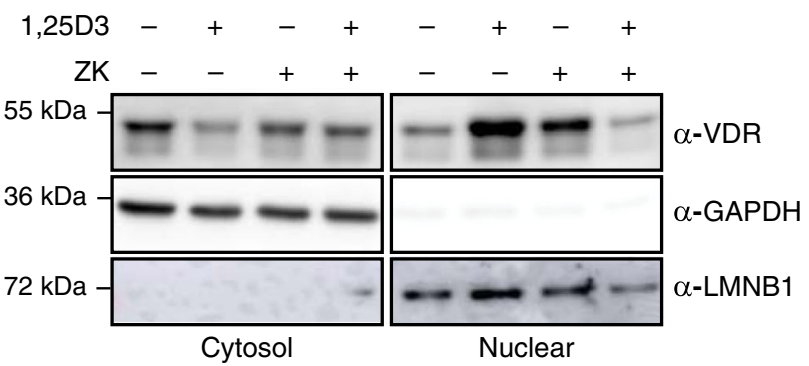

e

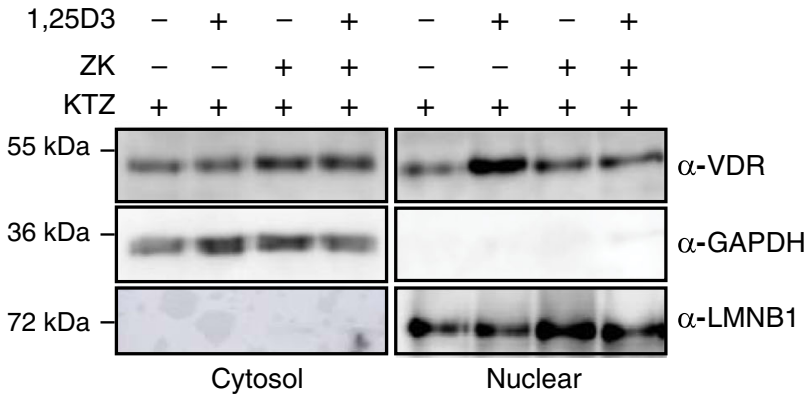

b

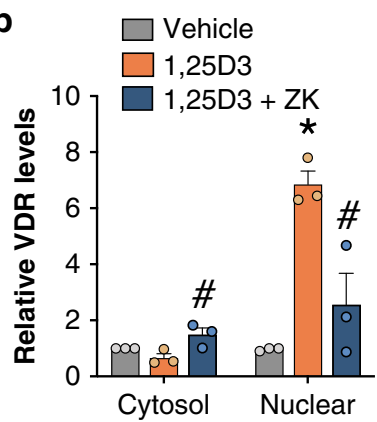

d $\square$ Vehicle $\square$ ZK
$\square 1,25$ D3 $\square 1,25$ D3 + ZK

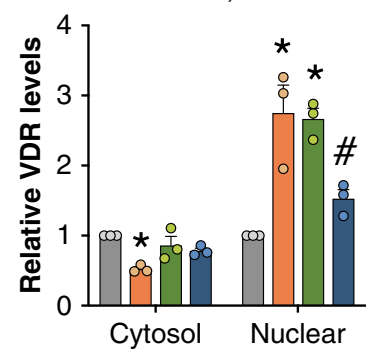

f

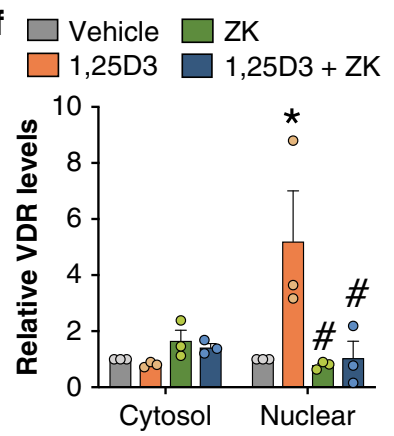

Fig. 3 Ligand-dependent VDR subcellular localization. Representative immunoblot (a) and quantification (b) of cytosolic and nuclear VDR in FB-789 cells

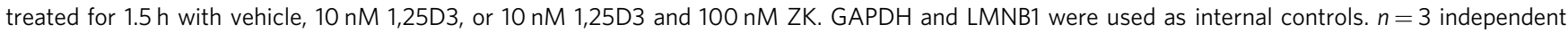
biological replicates/condition. Representative immunoblot (c and $\mathbf{e}$ ) and quantification ( $\mathbf{d}$ and $\mathbf{f}$ ) of cytosolic and nuclear VDR in extracts of IEC-18 cells treated for $1.5 \mathrm{~h}$ with vehicle, $100 \mathrm{nM}$ 1,25D3, $1 \mu \mathrm{M} \mathrm{ZK}$, or $100 \mathrm{nM} \mathrm{1,25D3}$ and $1 \mu \mathrm{M} \mathrm{ZK}$, pre-treated (e and f) or not (c and d) with $5 \mu \mathrm{M}$ ketoconazole (KTZ) for $2 \mathrm{~h}$. GAPDH and LMNB1 were used as internal controls. $n=3$ independent biological replicates/condition. Unprocessed blots in Source Data. Data in (b), (d), and (f) are represented as mean + s.e.m. ${ }^{\star} p<0.05$ vs. vehicle, $\# p<0.05$ vs. 1,25D3; two-way ANOVA with Tukey post-hoc test. The exact significant $p$-values are provided in Supplementary Table 4.

regions of Cyp24a1, Slc30a10, Slc37a2, Nkain1 and Atp2b1 ${ }^{28}$ was increased by $1,25 \mathrm{D} 3$ by at least 3 -fold in mouse intestine, but not by a $1,25 \mathrm{D} 3$ and $\mathrm{ZK}$ co-treatment (Fig. $5 \mathrm{c}$ ).

To gain insight into the mechanisms underlying $\mathrm{ZK}$ activities, genome-wide analysis of duodenum from mice treated for $6 \mathrm{~h}$ with vehicle, $1,25 \mathrm{D} 3$, or $1,25 \mathrm{D} 3$ and $\mathrm{ZK}$ was performed. The transcript levels of 3186 genes (1876 up and 1310 down) were modulated by at least 1.5 -fold in the intestine of 1,25D3-treated mice compared to vehicle (Fig. 5d). Pathways analyses revealed that $1,25 \mathrm{D} 3$ induces the expression of genes involved in protein digestion, protein and mineral absorption, and cell adhesion, whereas it reduces that of genes contributing to CYP-induced metabolism, arachidonic acid, cholesterol and linoleic acid metabolism, and bile secretion (Supplementary Fig 6 and Source Data). In addition, the expression of $>99 \%$ of the $1,25 \mathrm{D} 3$ regulated genes was normalized by a $\mathrm{ZK}$-cotreatment (Fig. $5 \mathrm{~d}$ ), and only 14 genes were differentially expressed in the intestine of mice co-treated with $1,25 \mathrm{D} 3$ and $\mathrm{ZK}$ compared to vehicle (Source Data file Fig. 5d), none being a known VDR target gene according to available databases ${ }^{28}$. To confirm that $\mathrm{ZK}$ efficiently blunts 1,25D3-induced gene expression, the transcript levels of the VDR target genes Cyp24a1, Slc30a10, Slc37a2, Nkain 1 and Atp2b1 were determined in the duodenum of additional wild type mice. Their levels were induced by at least 3 -fold by $1,25 \mathrm{D} 3$, but were similar in $1,25 \mathrm{D} 3$ and $\mathrm{ZK}$ co-treated mice and vehicle-treated mice (Fig. 5e). In addition, these transcripts were at least 5-fold higher in wild-type mice than in VDR-null mice when co-treated (Fig. 5e), and serum calcium levels remained physiological in co-treated wild-type mice whereas VDR-null mice were hypocalcemic (Fig. 5a). Thus, our results demonstrate that ZK does not fully abrogate VDR signaling in mice, but normalizes the expression of $1,25 \mathrm{D} 3$ induced target genes and hypercalcemia.

To determine the therapeutic potency of $\mathrm{ZK}$ after 1,25D3 intoxication, supra-physiological doses of $1,25 \mathrm{D} 3(1 \mu \mathrm{g} / \mathrm{kg} / \mathrm{day})$ were orally administered to mice for 2 days, followed by a 2-day treatment with $1,25 \mathrm{D} 3$ in the presence or absence of $\mathrm{ZK}(1 \mu \mathrm{g} / \mathrm{kg} /$ day) (Fig. 6a). Whereas mice treated with 1,25D3 alone were 

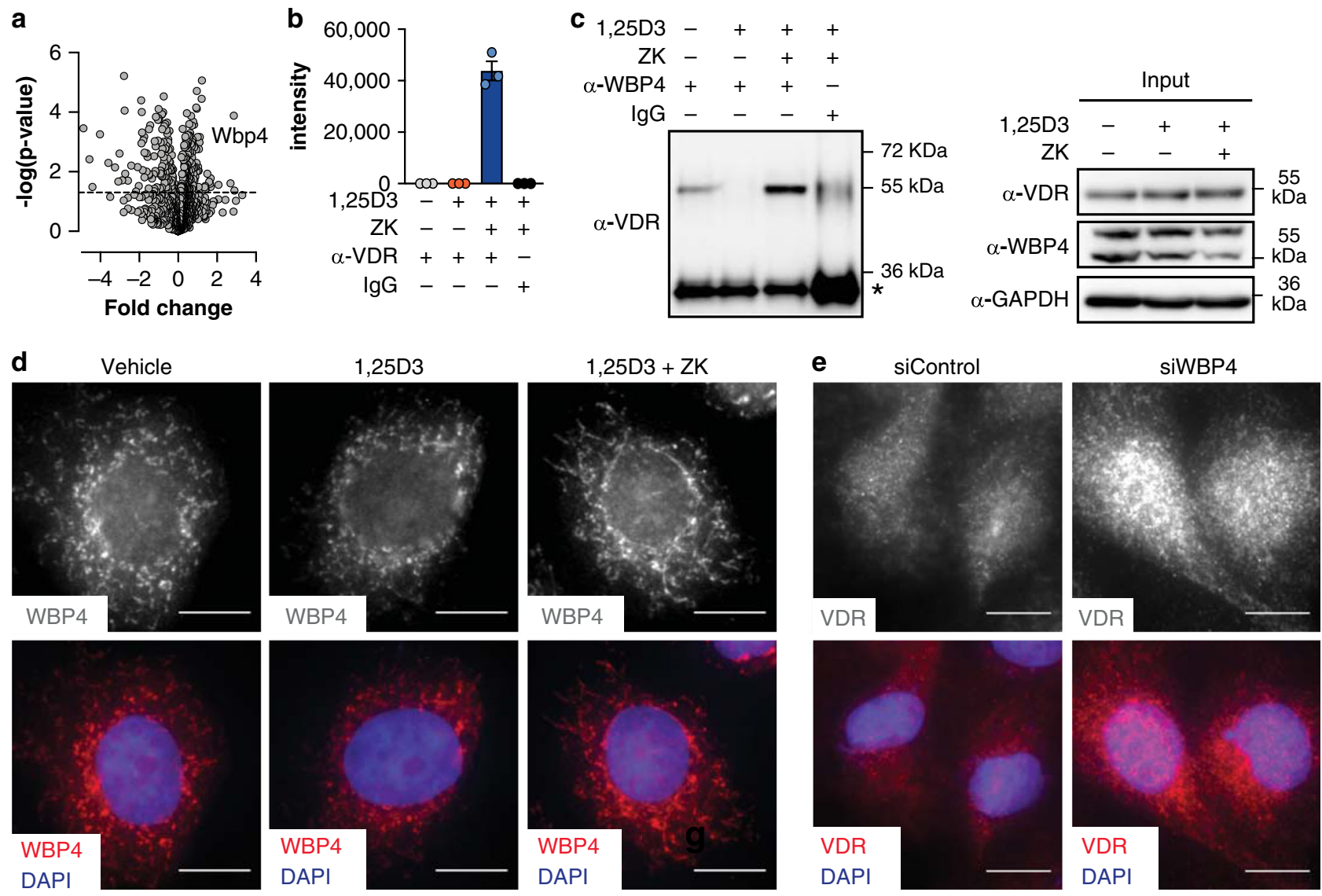

$\mathbf{f}$

\section{Cyp24a1}

S100g

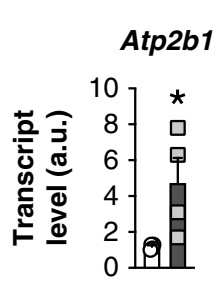

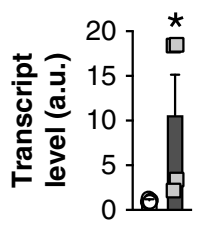

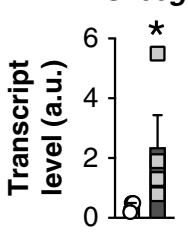

siControl

$\square$ siWBP4
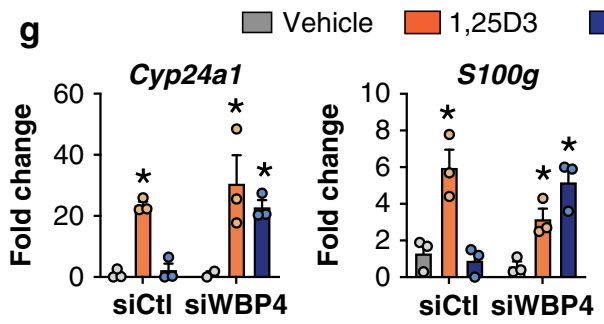

$1,25 \mathrm{D} 3+\mathrm{ZK}$

Fig. 4 VDR interactants, intracellular localization, and transcriptional activities. a Volcano plot representing peptides identified by mass-spectrometry of proteins bound to cytosolic VDR in cells co-treated with $100 \mathrm{nM} \mathrm{1,25D3}$ and $1 \mu \mathrm{M}$ ZK relative to vehicle-treated cells. $n=3$ technical replicates/condition. The dashed line represents a $p$-value of 0.05 . Source Data are provided as a Source Data file. $\mathbf{b}$ Abundance of WBP4 peptides determined by mass-spectrometry of VDR-immunoprecipitated cytosolic extracts of IEC-18 cells treated for $1.5 \mathrm{~h}$ with vehicle, $100 \mathrm{nM} 1,25 \mathrm{D} 3$ or $100 \mathrm{nM} 1,25 \mathrm{D} 3$ and $1 \mu \mathrm{MM}$ ZK. Cytosolic extracts from IEC-18 cells treated for $1.5 \mathrm{~h}$ with $100 \mathrm{nM} \mathrm{1,25D3}$ and $1 \mu \mathrm{M}$ ZK immunoprecipitated with IgG were used as a negative control. $n=3$ technical replicates/ condition. c Representative immunoblot of VDR in WBP4-immunoprecipitated cytosolic extracts of IEC-18 cells treated for $1.5 \mathrm{~h}$ with vehicle, $100 \mathrm{nM} \mathrm{1,25D3}$ or $100 \mathrm{nM} \mathrm{1,25D3}$ and $1 \mu \mathrm{M}$ ZK. Cytosolic extracts from IEC-18 cells treated for $1.5 \mathrm{~h}$ with $100 \mathrm{nM}$ 1,25D3 and $1 \mu \mathrm{M}$ ZK immunoprecipitated with Rabbit IgG were used as a negative control (left panel). *Indicates antibody light chains. Representative immunoblot of VDR, WBP4, and GAPDH (used as loading

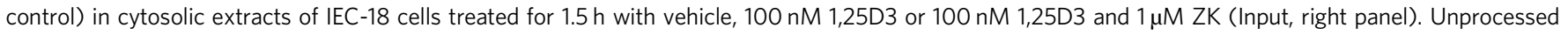
blots in Source Data. d Representative immunostaining of WBP4 in IEC-18 cells treated for $1.5 \mathrm{~h}$ with vehicle, 100 nM 1,25D3, or with 100 nM 1,25D3 and $1 \mu \mathrm{M}$ ZK (top panels). Superposition with DAPI-stained nuclei (bottom panels). Scale bar: $10 \mu \mathrm{m} . n=2$ independent biological replicates/condition. e Representative VDR immunostaining in hVDR-transfected IEC-18 cells silenced (siWBP4) or not (siControl) for WBP4 (top panels). Superposition with DAPI-stained nuclei (bottom panels). Scale bar: $10 \mu \mathrm{m} . n=3$ independent biological replicates/condition. $\mathbf{f}$ Transcript levels of Cyp24a1, S100g and Atp2b1 in IEC-18 cells silenced (siWBP4) or not (siControl) for WBP4. ${ }^{\star} p<0.05$ vs. siControl, Student's $t$-test. $n=4$ biological replicates/condition. $\mathbf{g}$ Transcript levels of Cyp24a1, S100g and Atp2b1 in IEC-18 cells transfected with WBP4 siRNA (siWBP4) and unrelated siRNA (siCtl) treated for $6 \mathrm{~h}$ with vehicle, 100 $\mathrm{nM}$ 1,25D3, or with $100 \mathrm{nM} \mathrm{1,25D3}$ and $1 \mu \mathrm{M}$ ZK. $n=3$ independent biological replicates/condition. ${ }^{*} p<0.05$ vs. vehicle, one-way ANOVA with Tukey post-hoc test. Data in (b), (f) and (g) are represented as mean + s.e.m. The exact significant $p$-values are provided in Supplementary Table 4.

hypercalcemic with suppressed PTH levels, a 2-day treatment with ZK normalized serum calcium and PTH levels (Fig. 6b, c). Moreover, ZK blunted 1,25D3-induced Cyp24a1 transcript levels in the duodenum and kidney (Fig. 6d, e). Thus, ZK normalizes acute and chronic hypercalcemia induced by vitamin $D_{3}$ intoxication.

\section{Discussion}

Various diseases are characterized by hypercalcemia secondary to high vitamin $\mathrm{D}_{3}$ levels. In addition to limit calcium and vitamin $\mathrm{D}$ intake, current treatments are based on drugs lowering serum calcium levels. However, they do not target VDR, are poorly efficient, and induce major side effects. 
a

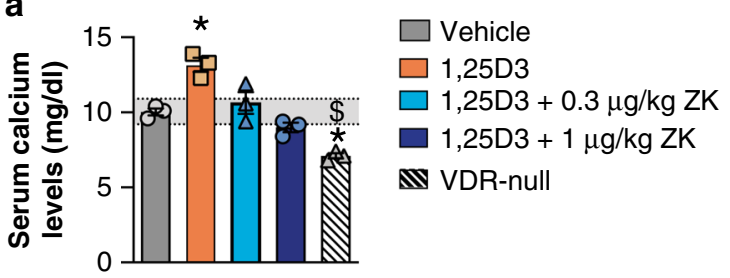

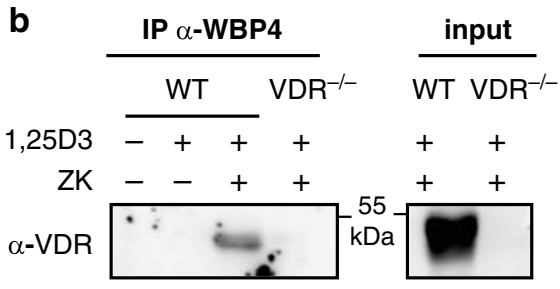

C
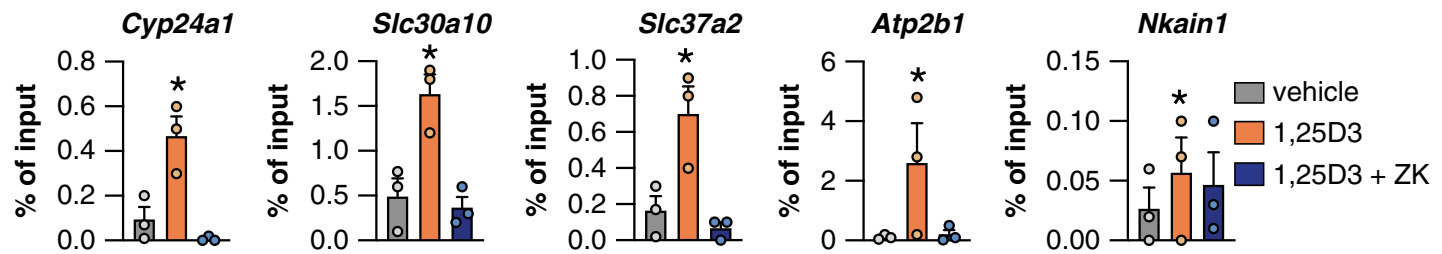

d

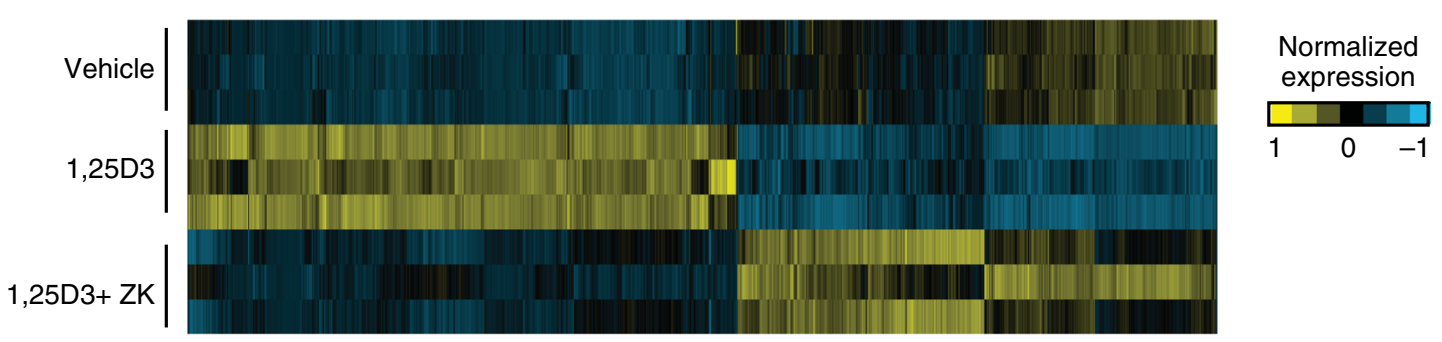

$\mathbf{e}$

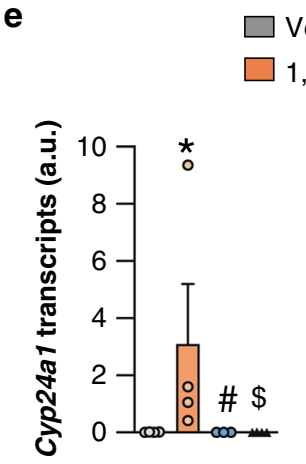

\begin{tabular}{l|l} 
Vehicle & wild type \\
1,25D3
\end{tabular}

$1,25 \mathrm{D} 3+\mathrm{ZK} \quad$ I Wild type

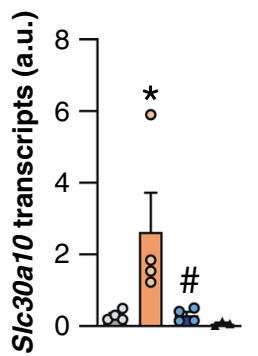

$\mathbb{N} 1,25 D 3+Z K \quad \mid V D R-n u l l$
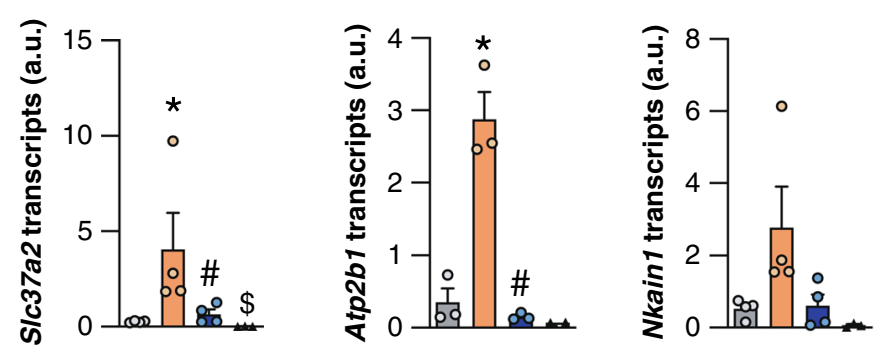

Fig. 5 ZK activities in mice. a Wild type mice were daily treated per os for 4 days with $1 \mu \mathrm{g} / \mathrm{kg} 1,25 \mathrm{D} 3,1 \mu \mathrm{g} / \mathrm{kg} 1,25 \mathrm{D} 3$ and $0.3 \mu \mathrm{g} / \mathrm{kg} \mathrm{ZK}, 1 \mu \mathrm{g} / \mathrm{kg}$ 1,25D3 and $1 \mu \mathrm{g} / \mathrm{kg}$ ZK or vehicle, and serum calcium levels were determined $24 \mathrm{~h}$ after the last administration. The gray area represents the normocalcemic range. Age-matched VDR-null mice were used as hypocalcemic controls. $n=3$ mice/condition. b Representative immunoblot of VDR in WBP4

immunoprecipitated (IP- $\alpha$ WBP4) or in total (input) extracts from kidney of wild type mice treated for $6 \mathrm{~h}$ with vehicle, $1 \mu \mathrm{g} / \mathrm{kg} 1,25 \mathrm{D} 3$, or $1 \mu \mathrm{g} / \mathrm{kg} 1,25 \mathrm{D} 3$ and $1 \mu \mathrm{g} / \mathrm{kg} \mathrm{ZK}$, and of VDR-null mice treated with $1 \mu \mathrm{g} / \mathrm{kg} 1,25 \mathrm{D} 3$ and $1 \mu \mathrm{g} / \mathrm{kg}$ ZK. Unprocessed blots in Source Data. c VDR ChIP-qPCR analysis of DNA segments encompassing vitamin D response elements of Cyp24a1, S/c30a10, S/c37a2, Atp2b1, and Nkain1 from duodenum of wild type mice treated for $1.5 \mathrm{~h}$ with vehicle, $1 \mu \mathrm{g} / \mathrm{kg} 1,25 \mathrm{D} 3$, and $1 \mu \mathrm{g} / \mathrm{kg} 1,25 \mathrm{D} 3$ and $1 \mu \mathrm{g} / \mathrm{kg}$ ZK. $n=3$ mice/condition. $\mathbf{d}$ Heatmap representing the mean-centered normalized transcript levels that were significantly different in the intestine of mice treated with 1,25D3 or with 1,25D3 and ZK, compared to vehicle. $n=3$ mice/condition. e Cyp24a1, Slc30a10, Slc37a2, Atp2b1 and Nkain1 transcript levels in duodenum of wild type mice treated for $6 \mathrm{~h}$ with vehicle, $1 \mu \mathrm{gg} / \mathrm{kg} 1,25 \mathrm{D} 3$, and $1 \mu \mathrm{g} / \mathrm{kg}$ $1,25 \mathrm{D} 3$ and $1 \mu \mathrm{g} / \mathrm{kg} \mathrm{ZK}$, and in VDR-null mice treated with $1 \mu \mathrm{g} / \mathrm{kg} 1,25 \mathrm{D} 3$ and $1 \mu \mathrm{g} / \mathrm{kg} \mathrm{ZK} . n=4$ wild type mice $/$ condition, except for Atp2b1 ( $n=3$ ). $n=3$ VDR-null mice/condition, except for Atp2b1 $(n=2)$. Data in (a), (c), and (e) are represented as mean + s.e.m. ${ }^{\star} p<0.05$ vs. vehicle, \#p<0.05 vs. $1,25 \mathrm{D} 3, \$ p<0.05$ vs. 1,25D3 and ZK, one-way ANOVA with Tukey post-hoc test. The exact significant $p$-values are provided in Supplementary Table 4.
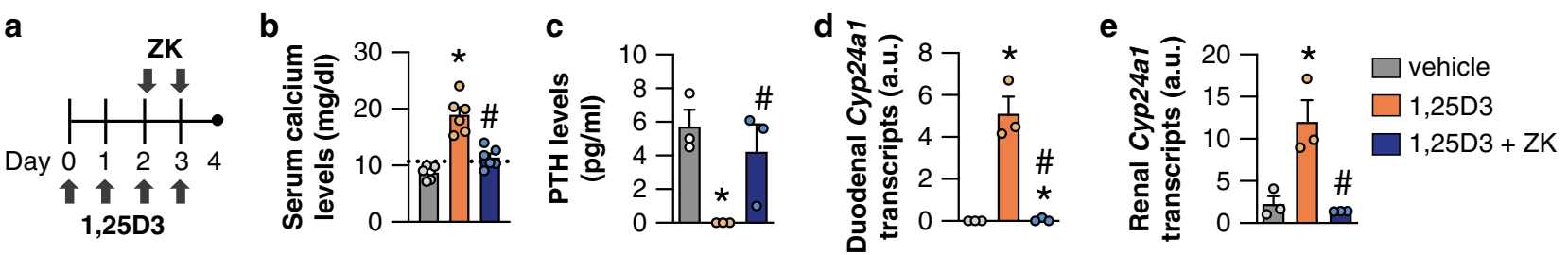

Fig. 6 ZK therapeutic effect in mice. a Schematic representation of 1,25D3 and ZK administration to mice. Serum calcium (b) and PTH (c) levels, and duodenal (d) and renal (e) relative Cyp24a1 transcript levels, $24 \mathrm{~h}$ after the last administration of vehicle, $1 \mu \mathrm{g} / \mathrm{kg} 1,25 \mathrm{D} 3$, or $1 \mu \mathrm{g} / \mathrm{kg} 1,25 \mathrm{D} 3 \mathrm{and} 1 \mu \mathrm{gg} / \mathrm{kg}$ ZK. Dashed line in (b) represents the maximal normo-calcemic concentration (10.7 mg/dL). b $n=6$ mice/condition. c-e $n=3$ mice/condition. Data are represented as mean + s.e.m. ${ }^{\star} p<0.05$ vs. vehicle, $\# p<0.05$ vs. 1,25D3, one-way ANOVA with Tukey post-hoc test. The exact significant $p$-values are provided in Supplementary Table 4. 
ZK, a carboxylic ester analog of $1,25 \mathrm{D} 3$, was shown to antagonize 1,25D3-induced VDR activity in cultured cells, but the underlying molecular mechanisms were poorly characterized $^{10,11,13-15}$ and its in vivo activities unknown.

Here, we show that ZK normalizes the expression of 1,25D3induced VDR target genes in rat intestinal cells and human fibroblasts. Unexpectedly, these genes were induced in various cell lines treated with $\mathrm{ZK}$, even though, in agreement with previous results $^{14}$, ZK did not promote the agonistic conformation of VDR $\mathrm{H} 12$ in vitro. We demonstrate that CYP24A1-generated ZK derivatives have VDR agonistic activities, whereas $\mathrm{ZK}$ is a pure antagonist.

Interestingly, we show that 1,25D3-induced VDR nuclear translocation is impaired by ZK. We identified proteins associated with VDR in the cytosol, and unraveled WBP4, as a cytosolic VDR interactant. WBP4 was previously reported as a nuclear protein within the spliceosome complex ${ }^{29}$, and its overexpression increased pre-mRNA splicing efficiency ${ }^{26}$. We demonstrate that the region of WBP4 encompassing two WW domains that are docking sites for proline-rich motifs ${ }^{27}$ interacts with VDR, and ZK enhances the interaction. As ZK stabilizes less efficiently than $1,25 \mathrm{D} 3$ the VDR NLS encompassing a diproline motif (154RPPVR-158), it is likely that ZK-bound VDR interacts with WBP4 through this region. Previous results showed that the affinity of WBP4 WW domains for splicing factors increased with the valency of proline-rich sequences ${ }^{25}$. However, as the concentration of the WBP4 polypeptides used in the microscale thermophoresis experiments to characterize WBP4/VDR interaction in the presence or absence of $\mathrm{ZK}$ did not allow to reach a saturation plateau, the binding mode between WBP4 and liganded- and unliganded-VDR remains to be determined.

Our results demonstrate that WBP4 is essential to maintain $\mathrm{VDR}$ in the cytosol and for ZK-induced VDR antagonistic activity. In contrast, it is dispensable for 1,25D3-induced VDR transcription and is not mandatory for RNA splicing, as the primers used to quantify various transcripts in WBP4-silenced cells spanned exon-exon junctions. Interestingly, we identified two major WBP4 isoforms that are differentially located in the cytosol and nucleus of various cell lines, in agreement with recent genome-wide studies suggesting that WBP4 is a multifunctional protein $^{30,31}$. Whether the shorter one, which is more abundant in the cytosol, selectively interacts with VDR requires further investigation.

Importantly, we demonstrate that serum calcium levels of mice treated with $1,25 \mathrm{D} 3$ to induce hypercalcemia were within the physiological range when co-treated with $\mathrm{ZK}$, and almost all intestinal genes modulated by $1,25 \mathrm{D} 3$ were unaffected. Moreover, a 2-day ZK treatment of 1,25D3-intoxicated mice normalized serum calcium and PTH levels. Thus, this compound, which selectively targets VDR, opens new therapeutic strategies.

Taken together, our results show that the vitamin $\mathrm{D}$ analog $\mathrm{ZK}$ impairs 1,25D3-induced VDR nuclear translocation by enhancing the interaction of the receptor with WBP4 in the cytosol, and prevents and/or normalizes 1,25D3-induced hypercalcemia in mice. Moreover, as ZK blunts 1,25D3-induced VDR target gene transcription in fibroblast from an IIH patient, but does not fully suppress VDR signaling in mice, this VDR antagonist represents a potent and safe therapeutic option for acute and chronic hypercalcemia secondary to hypervitaminosis D.

\section{Methods}

Chemical. 1,25-Dihydroxyvitamin D3 (17936, Sigma Aldrich) and ZK168281 (ZK, gift from the Medicinal Chemistry Department of Schering AG) were dissolved in absolute ethanol at $10^{-2} \mathrm{M}$ and stored at $-20^{\circ} \mathrm{C}$. Ketoconazole (KTZ, TOKU-E) was dissolved in DMSO at $10^{-2} \mathrm{M}$ and stored at $-20^{\circ} \mathrm{C}$.
Cell lines. Mycoplasma-free IEC-18 rat intestinal epithelial cells (American Type Culture Collection) were grown in Dulbecco's modified Eagle's medium (DMEM) $4.5 \mathrm{~g} / \mathrm{L}$ glucose supplemented with $5 \%$ fetal calf serum (FCS), $1 \mathrm{mM}$ sodium pyruvate $0.1 \mathrm{UI} / \mathrm{mL}$ insulin and $40 \mu \mathrm{g} / \mathrm{mL}$ gentamicin. The U2OS human bone osteosarcoma epithelial cells and the HeLa human cervical epithelial carcinoma cells were grown in DMEM $1 \mathrm{~g} / \mathrm{L}$ glucose supplemented with $5 \%$ FCS and $40 \mu \mathrm{g} / \mathrm{mL}$ gentamicin. Cells at $80 \%$ confluency were grown for $48 \mathrm{~h}$ in medium in which FCS was charcoal-treated.

Human fibroblasts. The collection and use of the human fibroblasts was performed in adherence with the principles of the declaration of Helsinki. Written informed consent of a 55-year-old man with elevated urine calcium and 1,25D3 levels in spite of a markedly low parathormone concentration was obtained for collection of clinical and laboratory data, DNA collection, and use of skin biopsy derived fibroblast (authorization 941 from the Ethical Committee from Caen University Hospital). The 25-hydroxy-vitamin $\mathrm{D}_{3} / 24,25$-dihydroxy-vitamin $\mathrm{D}_{3}$ blood ratio determined by liquid-chromatography tandem MS indicated a CYP24A1 deficiency ${ }^{18}$. Sanger sequencing of the CYP24A1 coding sequence revealed c.62del/p.(Pro21Argfs*8) (rs744432244) and c.427_429del/p.(Glu143del) (rs777676129) mutations in a compound heterozygous state (reference transcript NM_000782.5). Three mm skin punches obtained from the inner left arm were dissociated and cultured in Gibco ${ }^{\text {Tx }}$ Amniomax ${ }^{\text {Tx }}$ Medium (ThermoFisher Scientific, Waltham, Massachusetts, USA) for 10 days. Cells were then grown in DMEM/ Nutrient Mixture F-10 Ham (1:1) supplemented with 10\% FCS and $40 \mu \mathrm{g} / \mathrm{mL}$ gentamicin. FB-789 normal human primary fibroblasts (IGBMC, France) ${ }^{19}$ were maintained in Minimum Essential Medium (MEM) supplemented with 15\% FCS, non-essential amino acid and antibiotics $(40 \mu \mathrm{g} / \mathrm{mL}$ gentamicin, $100 \mathrm{UI} / \mathrm{mL}$ penicillin, and $100 \mu \mathrm{g} / \mathrm{mL}$ streptomycin).

Gene silencing. Small interference RNA (siRNA) transfection was performed following Dharmacon's protocol. Briefly, IEC-18 cells were seeded and grown overnight in serum-deprived growth medium to $80 \%$ confluency, transfected for $96 \mathrm{~h}$ with $1 \mu \mathrm{M}$ siRNA targeting rat WBP4 (Accell pool ID: E-087189-00-0050) or non-targeting siRNA (ID: D-001910-10-50) in Accell delivery media, and treated as indicated.

Mice. C57BL/6 J mice (WT) and VDR-null (VDR $\left.{ }^{-/-}\right)^{32}$ mice on a similar genetic background were housed in a temperature- and light-controlled animal facility and fed ad libitum (Safe diets, D04, France). Ten-week-old male mice were administered per os with $100 \mu \mathrm{L}$ of vehicle, 1,25D3 and/or ZK dissolved in oil (sunflower oil, Auchan). At the end of the treatment, blood was collected by inferior palpebral vein puncture, and mice were killed by cervical dislocation. Tissues were collected and immediately processed or frozen in liquid nitrogen. All animal experimental protocols were conducted in compliance with French and EU regulations on the use of laboratory animals for research, and approved by the IGBMC Ethical Committee and the French Ministry (\#10047-2017052615101492 and \#217762019082318288737).

Serum calcium and PTH levels. Blood was kept overnight at $4^{\circ} \mathrm{C}$ and centrifuged at $400 \mathrm{~g}$ for $10 \mathrm{~min}$ at $4^{\circ} \mathrm{C}$. Serum calcium and PTH levels were determined using colorimetric assays (MAK022, Sigma Aldrich and Ab230931, Abcam, respectively) according to the supplier's protocol.

RNA isolation and analysis. Total RNA was isolated from mouse tissue and cells using NucleoSpin kit reagents (Macherey-Nagel GmbH \& Co. KG) and TRI Reagent (Molecular Research Center, Inc.), respectively, according to the manufacturer's protocols. RNA was quantified by spectrophotometry (Nanodrop, Thermo Fisher), and cDNA prepared using $2 \mu \mathrm{g}$ of total RNA, random hexamers and SuperScriptII reverse transcriptase (Thermo Fisher) following the manufacturer's instructions. Quantitative PCR reactions were performed using the Light Cycler 480 SYBR Green I Master X2 Kit (Roche) according to the supplier's protocol. Oligonucleotides are listed in Supplementary Table 3.

Transcriptomic analysis. cDNA libraries were generated from $600 \mathrm{ng}$ of total RNA using the TruSeq Stranded mRNA LT Sample Preparation Kit (Illumina), according to the manufacturer's instructions, quantified and checked for quality using capillary electrophoresis. Fifty base pair single-read sequencing was performed on a Hiseq 4000 sequencer (Illumina) following the manufacturer's instructions. Image analysis and base calling were performed with RTA 2.7.7 and bcl2fastq 2.17.1.14 softwares. Adapter dimer reads were removed using DimerRemover. FastQC 0.11.2 was used to assess the quality of sequencing. Reads were mapped onto the mm10 assembly of the mouse genome using Tophat 2.1.133 and Bowtie2 2.3.4.3 34 . Only uniquely aligned reads were retained for further analyses. Quantification of gene expression was performed using HTSeq-0.11.0 ${ }^{35}$. Read counts were normalized across libraries by the method of Anders et al. ${ }^{36}$. Comparisons of the transcripts with more than 100 raw reads were performed by the method of Love et al. ${ }^{37}$ implemented in the DESeq2 Bioconductor library (DESeq2 v1.0.19). Resulting $p$-values were further adjusted for multiple testing. Genes were considered to be differentially expressed if the adjusted $p$-value was less than 0.05 
and the $\mid \log 2$ Fold-change $\mid>0.58$. Hierarchical clustering was performed using Cluster 3.0, and the heatmaps were visualized using the Java TreeView software Gene Ontology annotation was performed using clusterProfiler ${ }^{38}$.

Protein isolation. Harvested cultured cells and homogenized tissues (Precellys, Bertin instruments) were centrifuged at $400 \mathrm{~g}$ for $5 \mathrm{~min}$. Cell pellets were resuspended in radioimmunoprecipitation assay lysis buffer (RIPA) [50 mM Tris $\mathrm{pH}$ $7.5,1 \%$ Nonident P40, $0.5 \%$ sodium deoxycholate, $0.1 \%$ SDS, $150 \mathrm{mM} \mathrm{NaCl}, 5 \mathrm{mM}$ EDTA, $1 \mathrm{mM}$ PMSF, and phosphatase and protease inhibitor cocktails (PhosphoStop and Complete-Mini EDTA free; Roche)]. Lysates were cleared by centrifugation at $10,000 \mathrm{~g}$ for $10 \mathrm{~min}$ at $4{ }^{\circ} \mathrm{C}$, and supernatant protein concentrations were determined using Bradford Reagent (ab119216, Abcam) according to the manufacturer's instructions. For subcellular fractionation, cell pellets were resuspended in $200 \mu \mathrm{L}$ of $10 \mathrm{mM}$ HEPES, $60 \mathrm{mM} \mathrm{KCl}, 1 \mathrm{mM}$ EDTA, $0.075 \%$ (v/v) NP40, $1 \mathrm{mM}$ DTT, and $1 \mathrm{mM}$ PMSF (pH 7.6), and incubated on ice for $8 \mathrm{~min}$. After centrifugation at $400 \mathrm{~g}$ for $5 \mathrm{~min}$, supernatants were collected as cytosolic fractions. Pellets were washed in PBS, resuspended in $100 \mu \mathrm{L}$ of $20 \mathrm{mM}$ Tris $\mathrm{HCl}, 420 \mathrm{mM}$ $\mathrm{NaCl}, 1.5 \mathrm{mM} \mathrm{MgCl}_{2}, 0.2 \mathrm{mM}$ EDTA, $1 \mathrm{mM}$ PMSF and 25\% (v/v) glycerol ( $\mathrm{pH} 8.0$ ), and incubated for $10 \mathrm{~min}$ on ice. After centrifugation at $15,000 \mathrm{~g}$ for $10 \mathrm{~min}$, supernatants were collected as the nuclear fractions.

Immunoprecipitation. One mg of total (mouse tissue) or cytosolic (IEC-18 cells) protein extracts obtained from fresh material was incubated overnight with $10 \mu \mathrm{L}$ anti-VDR (D2K6W, Cell Signaling) or anti-WBP4 (Abcam) antibodies (Supplementary Table 3) in $500 \mu \mathrm{L}$ immunoprecipitation buffer $(50 \mathrm{mM}$ Tris $\mathrm{pH} 7.5$, $150 \mathrm{mM} \mathrm{NaCl}, 5 \%$ glycerol, $1 \% \mathrm{NP}-40$ ). Immunocomplexes recovered with Gcoupled agarose beads (Sigma Aldrich) were washed and eluted in loading buffer (30 mM Tris $\mathrm{HCl} \mathrm{pH} 6.8,1 \%$ sodium dodecyl sulfate, $2.5 \% \beta$-mercaptoethanol, $5 \%$ glycérol, and $0.001 \%$ bromophenol blue).

Mass Spectrometry analysis. Immunoprecipitated proteins were reduced, alky lated, and digested with trypsin at $37^{\circ} \mathrm{C}$ overnight. Peptides were analyzed using an Ultimate 3000 nano-RSLC (Thermo Scientific) coupled in line with an Orbitrap ELITE (Thermo Scientific). Briefly, peptides were separated on a C18 nano-column with a linear gradient of acetonitrile and analyzed using the Top 20 collisioninduced dissociation method. Data were processed by database searching against Rattus norvegicus Uniprot Proteome database (29944 sequences) with Maxquant 1.6.6.0 and Perseus 1.6.6.0. Precursor and fragment mass tolerance were set at $7 \mathrm{ppm}$ and $0.6 \mathrm{Da}$, respectively. Trypsin was set as enzyme, and up to two missed cleavages were allowed. Oxidation and $\mathrm{N}$-term acetylation were set as variable modification and carbamidomethylation as fixed modification. Proteins were identified with a minimum of two unique peptides and a false discovery rate $<1 \%$. Proteins identified in two out of three replicates were considered. $p$-values obtained by moderated $t$-test of median-normalized $\log 2$-data were transformed to a local false discovery rate of 0.05 .

SDS-PAGE analysis. Equal amounts of proteins were resolved under denaturing conditions by electrophoresis in $8-12 \%$ SDS-containing polyacrylamide gels (SDSPAGE) and transferred to nitrocellulose membranes (Trans-blot turbo transfer system, Bio-Rad) following the manufacturer's protocol. Membranes were incubated for $1 \mathrm{~h}$ at room temperature in $10 \mathrm{mM}$ Tris $\mathrm{pH} 7.4,0.05 \%$ Tween-20 (TBST) supplemented with $5 \%$ nonfat dry milk. Immunoblotting with antibodies (Supplementary Table 3) was performed overnight in TBST with 5\% bovine serum albumin (BSA), and immunocomplexes were revealed upon a $1 \mathrm{~h}$ incubation with horseradish peroxidase (HRP)-conjugated antibodies directed against rabbit Ig (Jackson ImmunoResearch) with an enhanced chemiluminescence detection system (ECLplus, GE Healthcare) and an ImageQuant LAS 4000 biomolecular imager (GE Healthcare). For co-immunoprecipitation experiments, membranes were incubated with mouse anti-rabbit IgG (L27A9, Conformation Specific, Cell signaling) for $1 \mathrm{~h}$ at room temperature before addition of the secondary antibodies. Immunodetected proteins were quantified with FIJI/ ImageJ distribution Software $^{39}$. The unprocessed scans of the immunoblots are available as a Source Data file.

Chromatin immunoprecipitation. Mouse duodenum was harvested and washed twice in ice-cold PBS, incubated in PBS containing 1\% paraformaldehyde (PFA, Electron Microscopy Sciences) for $10 \mathrm{~min}$, and quenched with $0.125 \mathrm{M}$ glycine at room temperature for $5 \mathrm{~min}$. Nuclei from cross-linked tissues were isolated in ChIP Buffer (ChIP-IT High Sensitivity, Active Motif) following the manufacturer's procedure and sonicated in $300-400$ bp DNA fragments. Thirty $\mu \mathrm{g}$ of chromatin was immunoprecipitated with anti-VDR antibodies (D2K6W, Cell Signaling) and DNA was recovered following the manufacturer's directions (ChIP-IT High Sensitivity, Active Motif). qPCR reactions were performed using the Light Cycler 480 SYBR Green I Master X2 Kit (Roche) according to the supplier's protocol. Oligonucleotides are listed in Supplementary Table 3.

Immunocytochemistry. Cells grown in 8-well Lab-Tek II RS Glass Chamber Slides (Thermo Fisher) were washed twice with PBS, fixed in $4 \%$ PFA for $15 \mathrm{~min}$ at room temperature, washed in PBS and permeabilized in PBS $0.2 \%$ Triton X-100 for $5 \mathrm{~min}$. After $1 \mathrm{~h}$ incubation in PBS-5\% BSA, primary antibodies (Supplementary Table 3) were added overnight at $4{ }^{\circ} \mathrm{C}$. After three washes in PBS, cells were incubated with fluorescent cyanine (Cy3)-conjugated anti-rabbit antibodies (Jackson ImmunoResearch Laboratories) for $1 \mathrm{~h}$ at room temperature and nuclei were stained with 4',6-Diamidino-2-phenylindole (DAPI; Sigma Aldrich). Slides were examined under an epifluorescence microscope (Leica), and images were acquired with a 16-bit Cool Snap FX camera by the Leica Application Suite X (LAS $\mathrm{X}$ ) software. Fluorescence intensity was determined using FIJI/ ImageJ distribution Software ${ }^{39}$

Intracellular calcium measurement. IEC-18 cells were grown in $\mathrm{Ca}^{2+}$-free medium [ $20 \mathrm{mM}$ Hepes, $40 \%$ (w/v) glucose, $140 \mathrm{mM} \mathrm{NaCl}, 5 \mathrm{mM} \mathrm{KCl}, 1 \mathrm{mM}$ $\left.\mathrm{MgCl}_{2}\right]$ in the presence of $1 \mu \mathrm{M}$ pluronic acid F-127 (Thermo Fisher) and $5 \mu \mathrm{M}$ Indo-1 AM calcium probe (Thermo Fisher) for $30 \mathrm{~min}$ at $37^{\circ} \mathrm{C}$, washed two times with $\mathrm{PBS}$, and incubated for $30 \mathrm{~min}$ at $37^{\circ} \mathrm{C}$ in $\mathrm{Ca}^{2+}$-free medium. Ratiometric calcium imaging was performed using an inverted Leica SP8 UV/Visible Laser Confocal Microscope equipped with a Leica HC PL APO $63 \times 1.4$ N.A. oil immersion objective. Cells were subjected to a $355 \mathrm{~nm}$ UV laser. Two confocal images in the spectral range $400-440 \mathrm{~nm}$ and $470-540 \mathrm{~nm}$ were simultaneously recorded every $5 \mathrm{~s}$ using HyD detectors in the counting mode. Variation of the intracellular calcium concentration was determined by the intensity ratio between the two emission bands with the FIJI/ ImageJ distribution Software ${ }^{39}$.

Biochemistry. DNA segments encoding His-tagged LBD of hVDR (amino acid 118-427) and of hRXRa (amino acid 223-462), and His-tagged hRXRa $\Delta$ NTD (amino acid 130-462) were inserted into pET15b. The cDNA encoding His-tagged hVDR (amino acid 1-427) was cloned into pET28b. Recombinant proteins were produced in Escherichia coli BL21 DE3 after induction with $1 \mathrm{mM} \mathrm{IPTG} \mathrm{(OD600}$ 0.7 ) at $23^{\circ} \mathrm{C}$ for $4 \mathrm{~h}$ (hVDR full-length and hRXRa $\Delta \mathrm{NTD}$ ) or at $18^{\circ} \mathrm{C}$ overnight (LBDs of hVDR and of hRXRa). Soluble proteins were purified using affinity chromatography columns (HisTrap FF crude, 17-5286-01, GE) followed by size exclusion chromatography (HiLoad Superdex 200, 28-9893-35 GE) equilibrated in $20 \mathrm{mM}$ Tris- $\mathrm{HCl}, \mathrm{pH} 8.0,250 \mathrm{mM} \mathrm{NaCl}, 5 \%$ glycerol, $2 \mathrm{mM}$ CHAPS and $1 \mathrm{mM}$ TCEP. Proteins were concentrated to $3-6 \mathrm{mg} / \mathrm{mL}$ with an Amicon Ultra $10 \mathrm{kDa}$ MWCO and the purity and homogeneity were assessed by SDS- and Native-PAGE For HDX-MS analysis, full-length hVDR and hRXRa $\triangle$ NTD were mixed in stoichiometric amounts and purified by size exclusion chromatography (HiLoad Superdex 200, 28-9893-35, GE) equilibrated in $20 \mathrm{mM}$ Tris pH 8.0, $75 \mathrm{mM} \mathrm{NaCl}$ $75 \mathrm{mM} \mathrm{KCl}, 2 \mathrm{mM}$ CHAPS, 5\% Glycerol, $4 \mathrm{mM} \mathrm{MgSO}_{4}, 1 \mathrm{mM}$ TCEP.

The cDNA encoding WBP4 amino acid 122-196 was inserted into pnEAtG ${ }^{40}$ to allow the expression of a N-terminal GST-tagged protein. The recombinant protein was produced in Escherichia coli BL21 DE3 after induction at an OD600 of $\sim 0.9$ with $0.5 \mathrm{mM}$ IPTG for $2.5 \mathrm{~h}$ at $20^{\circ} \mathrm{C}$. Soluble proteins were purified by glutathione sepharose (GE) chromatography, followed, after GST clivage by thrombin proteolysis, by size exclusion chromatography (HiLoad Superdex 200, 28-9893-35 GE) equilibrated in $20 \mathrm{mM}$ Hepes pH 7.5, $250 \mathrm{mM} \mathrm{NaCl}, 5 \%$ glycerol, $2 \mathrm{mM}$ CHAPS, and $1 \mathrm{mM}$ TCEP. The recombinant proteins were concentrated to $2-5 \mathrm{mg} / \mathrm{mL}$ with an Amicon Ultra $3 \mathrm{kDa}$ MWCO and their purity and homogeneity were assessed by SDS-PAGE.

Surface plasmon resonance. Measurements were performed with a Biacore T100 sensitivity enhanced T200 equipment (GE Healthcare) using CM5 series S sensor chip. hRXRa LBD monomers were immobilized on the chip surface in the range of 400-500 response unit using a standard amino-coupling protocol in $10 \mathrm{mM}$ Na-acetate buffer $\mathrm{pH}$ 5.5. The running buffer was $50 \mathrm{mM}$ Tris $\mathrm{pH} 7.5$, $150 \mathrm{mM} \mathrm{NaCl}, 1 \mathrm{mM}$ TCEP, $0.005 \%$ Tween $20 ; 1 \mathrm{M}$ sodium chloride solution was used for regeneration. hVDR LBD $(1-30 \mu \mathrm{M})$ was incubated with a 3 -fold excess of ligand, and interactions between immobilized-hRXR $\alpha$ LBD were analyzed. The association and dissociation phase were $120 \mathrm{~s}$. After subtracting the reference and buffer signal, the data were fit to a steady state binding model using the Biacore T200 Evaluation software (GE Healthcare).

HDX-MS. HDX-MS experiments were performed following the recommendations described by Masson et al ${ }^{41}$. Full-length hVDR/hRXRa $\Delta$ NTD heterodimers $(10 \mu \mathrm{M})$ were incubated with a 10 -fold excess of ligand or an equal volume of ethanol (vehicle) for $30 \mathrm{~min}$ at room temperature. Exchange reactions, performed with a CTC PAL sample handling robot (LEAP Technologies), were conducted by incubating 40 picomole of protein in $50 \mu \mathrm{l}$ of $\mathrm{D}_{2} \mathrm{O}$ buffer $(50 \mathrm{mM}$ Tris $\mathrm{pH} 8.0$, $200 \mathrm{mM} \mathrm{NaCl}, 2 \%$ Glycerol, $1 \mathrm{mM}$ TCEP) for $30,60,180,600$, or $1800 \mathrm{~s}$. The exchange reaction was quenched by the addition of $50 \mu \mathrm{l} 3 \mathrm{M}$ Urea containing $0.1 \%$ TriFluoro Acetic acid followed by immediate injection into a Aspergillopepsin protease $2.1 \times 20 \mathrm{~mm}$ column (Affipro) for protein digestion $\left(2 \mathrm{~min}\right.$ at $24^{\circ} \mathrm{C}$ ). Peptic digest was injected on a Waters nanoACQUITY UPLC System, where peptides were first desalted by trapping for $3 \mathrm{~min}$ on a VanGuard Pre-Column Acquity UPLC BEH C18 $(1.7 \mu \mathrm{m} ; 2.1 \times 5 \mathrm{~mm})$, and eluted over 9 min with $5-40 \%$ ( $\mathrm{vol} / \mathrm{vol}$ ) acetonitrile (containing $0.1 \%$ formic acid) gradient into a Waters Synapt G2-Si mass spectrometer. Peptide separation was conducted at $0.1{ }^{\circ} \mathrm{C}$. All exchange reactions were performed in triplicates. As a reference, peptides from three non- 
deuterated samples were identified using the ProteinLynx Global Server (PLGS Waters, UK). Peptides with an intensity over 5000 , a mass error $<5 \mathrm{ppm}$ and present in at least two of the three data acquisitions were pooled and imported into the DynamX data analysis software (Waters, UK). After a first round of automated spectral processing using DynamX, each peptide was inspected manually for suitability for further analysis. For the full-length hVDR, a total of 179 peptides were identified with a $92.1 \%$ coverage and a mean redundancy of 3.99 per amino acid. For hRXR $\alpha \Delta$ NTD, a total of 127 peptides were identified with an $88.7 \%$ coverage and a mean redundancy of 3.98 per amino acid. MEMHDX software was used to identify statistically significant changes of deuterium uptake that occurred upon compound binding ${ }^{42}$. The mean deuteration level per amino acid was calculated using Matlab (Mathworks) and subsequently mapped onto the crystal structures with PyMOL (Schrodinger LLC). The cryoEM structure ${ }^{19}$ was used for the representation of the hVDR/hRXRa LBD heterodimer. HDX-MS data have been deposited to the ProteomeXchange Consortium via the PRIDE partner repository ${ }^{43}$

Native PAGE analysis. Recombinant hVDR full-length was mixed with a 5-fold molar excess of hWBP4 polypeptide (amino acid 122-196) in the presence of two equivalents of $\mathrm{ZK}$. Then, $5 \mu \mathrm{g}$ of proteins were loaded on a $4-15 \%$ gradient GE Healthcare PhastGel ${ }^{\mathrm{Tw}}$ with Native PhastGel Buffer Strips (GE) following the manufacturer's protocol and revealed by Coomassie Brilliant Blue (CBB) staining.

Microscale thermophoresis. Measurements were performed with a Monolith NT.115 instrument (NanoTemper Technologies GmbH). Recombinant hVDR fulllength and hWBP4 polypeptide (amino acid 122-196) were prepared in $20 \mathrm{mM}$ Hepes pH 7.5, $200 \mathrm{mM} \mathrm{NaCl}$, 2\% Glycerol, $1 \mathrm{mM}$ TCEP, and $0.05 \%$ Tween 20 . The full-length hVDR was labeled with Red-NHS second generation labeling kit (NanoTemper) and incubated with ZK. The labeling procedure and the subsequent removal of free dye were performed within $1 \mathrm{~h}$. The solution of unlabeled WBP4 was serially diluted from a concentration of $100 \mu \mathrm{M}$ down to $1 \mathrm{nM}$ in the presence of $10 \mathrm{nM}$ labeled receptor. Measurements were made with standard glass capillaries (Nanotemper) at $25^{\circ} \mathrm{C}$, at $40 \%$ LED excitation and $80 \%$ MST power. Isotherms were averaged over three consecutive measurements and fitted according to the law of mass action with a 1:1 stoechiometry to yield the apparent $\mathrm{Kd}$, by using the NanoTemper Analysis 2.2.4 software.

Data analysis. No inclusion/exclusion criteria, and no method of randomization were used in this study. No blinding was used for animal studies. Data are represented as mean + standard error of mean (s.e.m.). The samples followed a normal distribution, and the variances were similar. Statistical comparisons of data between two groups were made by a Student's $t$-test and those between three and more by one-way ANOVA followed by a post-hoc analysis (Tukey's test). Data were considered to be statistically significant if $p<0.05$, and are indicated by *, $\$$ or \# in the figures (GraphPad Software Prism 8). The exact significant $p$-values are provided in Supplementary Table 4.

Reporting summary. Further information on research design is available in the Nature Research Reporting Summary linked to this article.

\section{Data availability}

RNA sequencing raw data are available in GEO database (GSE141985). Mass spectrometry raw data of IEC-18 cells are available as a Source Data file Fig. 3a. HDX-MS raw data are available via ProteomeXchange with identifier PXD019810. All relevant data are available from the authors. Source data are provided with this paper.

Received: 8 January 2020; Accepted: 12 November 2020; Published online: 07 December 2020

\section{References}

1. Fleet, J. C. The role of vitamin D in the endocrinology controlling calcium homeostasis. Mol. Cell Endocrinol. 453, 36-45 (2017).

2. Christakos, S., Dhawan, P., Verstuyf, A., Verlinden, L. \& Carmeliet, G. Vitamin D: metabolism, molecular mechanism of action, and pleiotropic effects. Physiol. Rev. 96, 365-408 (2016).

3. Bikle, D. \& Christakos, S. New aspects of vitamin D metabolism and actionaddressing the skin as source and target. Nat. Rev. Endocrinol. 16, 234-252 (2020).

4. Meir, T. et al. Deletion of the vitamin D receptor specifically in the parathyroid demonstrates a limited role for the receptor in parathyroid physiology. Am. J. Physiol. Ren. Physiol. 297, F1192-F1198 (2009).

5. Schlingmann, K. P. et al. Mutations in CYP24A1 and idiopathic infantile hypercalcemia. N. Engl. J. Med. 365, 410-421 (2011).
6. Figueres, M. L. et al. Kidney function and influence of sunlight exposure in patients with impaired 24-hydroxylation of vitamin D due to CYP24A1 mutations. Am. J. Kidney Dis. 65, 122-126 (2015).

7. Carpenter, T. O. CYP24A1 loss of function: clinical phenotype of monoallelic and biallelic mutations. J. Steroid Biochem. Mol. Biol. 173, 337-340 (2017).

8. Marcinowska-Suchowierska, E., Kupisz-Urbanska, M., Lukaszkiewicz, J., Pludowski, P. \& Jones, G. Vitamin D toxicity-a clinical perspective. Front. Endocrinol. (Lausanne) 9, 550 (2018).

9. Leyssens, C., Verlinden, L. \& Verstuyf, A. The future of vitamin D analogs. Front. Physiol. 5, 122 (2014)

10. Bury, Y., Steinmeyer, A. \& Carlberg, C. Structure activity relationship of carboxylic ester antagonists of the vitamin D(3) receptor. Mol. Pharm. 58, 1067-1074 (2000).

11. Herdick, M., Steinmeyer, A. \& Carlberg, C. Carboxylic ester antagonists of 1alpha,25-dihydroxyvitamin $\mathrm{D}(3)$ show cell-specific actions. Chem. Biol. 7 , 885-894 (2000).

12. Perakyla, M., Molnar, F. \& Carlberg, C. A structural basis for the speciesspecific antagonism of 26,23-lactones on vitamin D signaling. Chem. Biol. 11, $1147-1156$ (2004)

13. Lempiainen, H., Molnar, F., Macias Gonzalez, M., Perakyla, M. \& Carlberg, C. Antagonist- and inverse agonist-driven interactions of the vitamin $\mathrm{D}$ receptor and the constitutive androstane receptor with corepressor protein. Mol. Endocrinol. 19, 2258-2272 (2005).

14. Belorusova, A. Y., Chalhoub, S., Rovito, D. \& Rochel, N. Structural analysis of VDR complex with ZK168281 Antagonist. J. Med. Chem. 63, 9457-9463 (2020).

15. Vaisanen, S., Perakyla, M., Karkkainen, J. I., Steinmeyer, A. \& Carlberg, C. Critical role of helix 12 of the vitamin $\mathrm{D}(3)$ receptor for the partial agonism of carboxylic ester antagonists. J. Mol. Biol. 315, 229-238 (2002).

16. Laverny, G. et al. Synthesis and anti-inflammatory properties of 1alpha,25dihydroxy-16-ene-20-cyclopropyl-24-oxo-vitamin D3, a hypocalcemic, stable metabolite of 1alpha,25-dihydroxy-16-ene-20-cyclopropyl-vitamin D3. J. Med. Chem. 52, 2204-2213 (2009).

17. Muindi, J. R. et al. CYP24A1 inhibition enhances the antitumor activity of calcitriol. Endocrinology 151, 4301-4312 (2010).

18. Molin, A. et al. CYP24A1 mutations in a cohort of hypercalcemic patients: evidence for a recessive trait. J. Clin. Endocrinol. Metab. 100, E1343-E1352 (2015).

19. Ueda, T., Compe, E., Catez, P., Kraemer, K. H. \& Egly, J. M. Both XPD alleles contribute to the phenotype of compound heterozygote xeroderma pigmentosum patients. J. Exp. Med. 206, 3031-3046 (2009).

20. Rochel, N. \& Molnar, F. Structural aspects of vitamin D endocrinology. Mol Cell Endocrinol. 453, 22-35 (2017).

21. Orlov, I., Rochel, N., Moras, D. \& Klaholz, B. P. Structure of the full human RXR/VDR nuclear receptor heterodimer complex with its DR3 target DNA. EMBO J. 31, 291-300 (2012).

22. Rochel, N. et al. Common architecture of nuclear receptor heterodimers on DNA direct repeat elements with different spacings. Nat. Struct. Mol. Biol. 18, 564-570 (2011).

23. Zheng, J. et al. HDX reveals the conformational dynamics of DNA sequence specific VDR co-activator interactions. Nat. Commun. 8, 923 (2017).

24. Michigami, T. et al. Identification of amino acid sequence in the hinge region of human vitamin D receptor that transfers a cytosolic protein to the nucleus. J. Biol. Chem. 274, 33531-33538 (1999).

25. Klippel, S. et al. Multivalent binding of formin-binding protein 21 (FBP21)tandem-WW domains fosters protein recognition in the pre-spliceosome. $J$. Biol. Chem. 286, 38478-38487 (2011).

26. Huang, X. et al. Structure and function of the two tandem WW domains of the pre-mRNA splicing factor FBP21 (formin-binding protein 21). J. Biol. Chem. 284, 25375-25387 (2009)

27. Henning, L. M. et al. A new role for FBP21 as regulator of Brr2 helicase activity. Nucleic Acids Res. 45, 7922-7937 (2017).

28. Lee, S. M. et al. 1,25-Dihydroxyvitamin D3 controls a cohort of vitamin D receptor target genes in the proximal intestine that is enriched for calciumregulating components. J. Biol. Chem. 290, 18199-18215 (2015).

29. Bertram, K. et al. Cryo-EM structure of a pre-catalytic human spliceosome primed for activation. Cell 170, 701-713 e711 (2017).

30. Chapple, C. E. et al. Extreme multifunctional proteins identified from a human protein interaction network. Nat. Commun. 6, 7412 (2015).

31. Bassaganyas, L. et al. New factors for protein transport identified by a genome-wide CRISPRi screen in mammalian cells. J. Cell Biol. 218, 3861-3879 (2019).

32. Huet, T. et al. A vitamin D receptor selectively activated by gemini analogs reveals ligand dependent and independent effects. Cell Rep. 10, 516-526 (2015).

33. Kim, D. et al. TopHat2: accurate alignment of transcriptomes in the presence of insertions, deletions and gene fusions. Genome Biol. 14, R36 (2013). 
34. Langmead, B. \& Salzberg, S. L. Fast gapped-read alignment with Bowtie 2. Nat. Meth. 9, 357-359 (2012)

35. Anders, S., Pyl, P. T. \& Huber, W. HTSeq-a Python framework to work with high-throughput sequencing data. Bioinformatics 31, 166-169 (2015).

36. Anders, S. \& Huber, W. Differential expression analysis for sequence count data. Genome Biol. 11, R106 (2010).

37. Love, M. I., Huber, W. \& Anders, S. Moderated estimation of fold change and dispersion for RNA-seq data with DESeq2. Genome Biol. 15, 550 (2014).

38. Yu, G., Wang, L. G., Han, Y. \& He, Q. Y. clusterProfiler: an R package for comparing biological themes among gene clusters. OMICS 16, 284-287 (2012).

39. Schindelin, J. et al. Fiji: an open-source platform for biological-image analysis. Nat. Meth. 9, 676-682 (2012).

40. Busso, D. et al. Expression of protein complexes using multiple Escherichia coli protein co-expression systems: a benchmarking study. J. Struct. Biol. 175, 159-170 (2011).

41. Masson, G. R. et al. Recommendations for performing, interpreting and reporting hydrogen deuterium exchange mass spectrometry (HDX-MS) experiments. Nat. Meth. 16, 595-602 (2019).

42. Hourdel, V. et al. MEMHDX: an interactive tool to expedite the statistical validation and visualization of large HDX-MS datasets. Bioinformatics 32, 3413-3419 (2016).

43. Perez-Riverol, Y. et al. The PRIDE database and related tools and resources in 2019: improving support for quantification data. Nucleic Acids Res. 47, D442-D450 (2019).

44. Rochel, N., Wurtz, J. M., Mitschler, A., Klaholz, B. \& Moras, D. The crystal structure of the nuclear receptor for vitamin D bound to its natural ligand. Mol. Cell 5, 173-179 (2000).

\section{Acknowledgements}

We thank the IGBMC animal house facility, molecular biology, cell culture and antibody services, proteomic and imaging platforms, and GenomEast, a member of the 'France Génomique' consortium (ANR-10-INBS-0009), as well as R. Lutzing, C. Kostmann, C. Peluso-Iltis, and M. Aubert for excellent technical assistance, and P. Antony for helpful discussions. We acknowledge the Medicinal Chemistry Department of Schering AG (Bayer) for the ZK compound. This work was supported by INSERM, CNRS, Unistra and IGBMC, and by an INSERM young researcher fellowship and French state funds from Agence Nationale de la Recherche ANR-VARaD to G.L. and the grant ANR-10LABX-0030-INRT, a French State fund managed by the Agence Nationale de la Recherche under the frame program Investissements d'Avenir ANR-10-IDEX-0002-02. A.Y.B. is a fellow of the AstraZeneca R\&D post-doctoral program, and A.I.R. an IGBMC International $\mathrm{PhD}$ Programme fellow supported by LabEx INRT funds.

\section{Author contributions}

D.R., N.R., G.L., and D.M. conceived the study and analyzed the results. D.R. performed in vitro and in vivo experiments. A.Y.B. performed and analyzed HDX-MS. S.C. produced proteins used for HDX-MS and performed SPR. A.I.R. analyzed the sequencing data. E.G. helped to design and analyze fluorescent microscopy experiments. A.M. provided FB-CYP. A.L. discussed the results. N.R., G.L., and D.M. wrote the manuscript with input from all the authors. All authors edited the manuscript and approved the final manuscript.

\section{Competing interests}

The authors declare no competing interests.

\section{Additional information}

Supplementary information is available for this paper at https://doi.org/10.1038/s41467020-20069-4.

Correspondence and requests for materials should be addressed to G.L. or D.M.

Peer review information Nature Communications thanks Carsten Carlberg, and the other, anonymous, reviewer(s) for their contribution to the peer review of this work. Peer reviewer reports are available.

Reprints and permission information is available at http://www.nature.com/reprints

Publisher's note Springer Nature remains neutral with regard to jurisdictional claims in published maps and institutional affiliations.

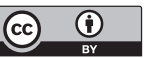

Open Access This article is licensed under a Creative Commons Attribution 4.0 International License, which permits use, sharing, adaptation, distribution and reproduction in any medium or format, as long as you give appropriate credit to the original author(s) and the source, provide a link to the Creative Commons license, and indicate if changes were made. The images or other third party material in this article are included in the article's Creative Commons license, unless indicated otherwise in a credit line to the material. If material is not included in the article's Creative Commons license and your intended use is not permitted by statutory regulation or exceeds the permitted use, you will need to obtain permission directly from the copyright holder. To view a copy of this license, visit http://creativecommons.org/ licenses/by/4.0/.

(C) The Author(s) 2020 